Feedback and Job Search Processes 1

\title{
Does Feedback Matter for Job Search Self-Regulation? It Depends on Feedback Quality
}

\author{
Nitya Chawla \\ Department of Management and Organizations \\ University of Arizona \\ 1130 E. Helen Street, McClelland Hall 405 \\ Tucson, AZ \\ 85721-0108 \\ Phone: 520.621 .3583 \\ Email: nityac@email.arizona.edu \\ Allison S. Gabriel \\ Department of Management and Organizations \\ University of Arizona \\ 1130 E. Helen Street, McClelland Hall 405 \\ Tucson, AZ \\ 85721-0108 \\ Phone: 570.621.1390 \\ Email: asgabriel@email.arizona.edu \\ Serge P. da Motta Veiga \\ Department of Management \\ American University \\ 4400 Massachusetts Avenue NW \\ Washington, DC \\ 20016 \\ Phone: 202.885.1489 \\ Email: damottav@american.edu \\ Jerel E. Slaughter \\ Department of Management and Organizations \\ University of Arizona \\ 1130 E. Helen Street, McClelland Hall 405 \\ Tucson, AZ \\ 85721-0108 \\ Phone: 520.621 .7632 \\ Email: jslaught@email.arizona.edu
}

Note. A previous version of this paper was presented at the 2017 Annual Conference of the Academy of Management in Atlanta, GA. We thank Nathan Podsakoff for his valuable comments in developing the supplemental study presented in this paper, and Maria Kraimer and our two anonymous reviewers for their constructive (high quality) feedback. Correspondence should be directed to Nitya Chawla, Department of Management and Organizations, Eller College of Management, University of Arizona; email: nityac@email.arizona.edu. 
Feedback and Job Search Processes 2

\begin{abstract}
Job search represents a dynamic process through which job seekers must consistently engage in effective self-regulation. Although scholars have increasingly begun to theorize and conceptualize the job search in this manner, little is known about what fosters effective selfregulation week-to-week. In light of this theoretical gap, we integrate self-regulation theory with the feedback literature to examine how feedback quality influences affective, cognitive, and behavioral regulatory processes in job search. Furthermore, we examine feedback self-efficacy (i.e., how efficacious a job seeker feels with respect to processing and implementing feedback received during the job search) as a stable, person-level moderator of these within-person relationships. In a sample of job seekers surveyed once a week for seven weeks, results indicate that receiving high quality feedback has a direct influence on positive and negative affective reactions tied to the job search, influencing subsequent positive (i.e., metacognitive strategies) and negative (i.e., affective rumination) cognitive processes. Metacognitive strategies, in turn, impact both the number of résumés sent and hours spent job seeking each week. Moreover, lower feedback self-efficacy amplifies the relationship between feedback quality and negative affective reactions. Our results highlight the importance of high quality feedback in helping job seekers effectively regulate week-to-week.
\end{abstract}

Keywords: job search; feedback; self-efficacy; self-regulation; weekly study 
The job search process can be highly emotional (Turban, Stevens, \& Lee, 2009), typified by anxiety and frustration when job seeking times are tough, and excitement and enthusiasm when things are going well. Therefore, in order to maintain their effort during the job search, job seekers must continuously manage their emotions, cognitions, and motivations (da Motta Veiga \& Gabriel, 2016; Turban et al., 2009). To this end, much of the research examining job search has characterized it as dynamic and self-regulated in nature, and studies adopting this approach have found that self-perceptions, cognitive processes, and behaviors vary weekly for job seekers (e.g., da Motta Veiga \& Gabriel, 2016; Kanfer, Wanberg, \& Kantrowitz, 2001; Liu, Wang, Liao, \& Shi, 2014; Wanberg, Zhu, Kanfer, \& Zhang, 2012; Wanberg, Zhu, \& van Hooft, 2010).

From a self-regulatory perspective, job seekers adjust their goal-directed behaviors as they continuously receive information regarding their job search progress (Liu et al., 2014; Lopez-Kidwell, Grosser, Dineen, \& Borgatti, 2013). Typically, such information arises from the socio-contextual environment, particularly through feedback from job search (Kanfer et al., 2001; Liu et al., 2014; Lopez-Kidwell et al., 2013; Sun, Song, \& Lim, 2013; Wanberg et al., 2010). For example, if job seekers receive rejection emails that detail the cause for not receiving the job(s), it is likely that this feedback will prompt them to adjust their goal-directed job seeking behaviors (Ilies \& Judge, 2005), potentially also influencing their ultimate employment goal. In fact, when Kanfer et al. (2001) first conceptualized the job search as a self-regulatory process, the authors noted that, "over time, job search behavior may change in direction or intensity as self-reactions or feedback from the environment influence self-regulatory components, such as employment goals and search strategies" (p. 838; italics added for emphasis). Nevertheless, despite prior theorizing regarding the role of feedback as a critical antecedent to self-regulation, research has yet to examine how and why feedback prompts self-regulatory efforts on a dynamic 
(i.e., week-to-week) basis, despite calls to study this phenomenon directly (e.g., da Motta Veiga \& Gabriel, 2016; da Motta Veiga \& Turban, 2014; Wanberg, Glomb, Song, \& Sorenson, 2005).

The current study makes three contributions to the job search literature. First, we examine for the first time the role of feedback quality during the job search process. Drawing from theorizing pertaining to the feedback environment (e.g., Steelman, Levy, \& Snell, 2004), we operationalize feedback quality to capture the extent to which the job search feedback provided is useful and "provides information on the specific goal-related behaviors and processes that result in performance outcomes" (i.e., job search success; Whitaker \& Levy, 2012, p. 161; see also Dahling, Gabriel, \& MacGowan, 2017) ${ }^{1}$. Within job search, we posit that it is crucial to focus on feedback quality as high quality feedback yields informational value to a greater extent (Steelman et al., 2004; Wang, Burlacu, Truxillo, James, \& Yao, 2015) and should be particularly useful to job seekers as they evaluate the effectiveness of their search strategies and behaviors. Further, the informational value of feedback determines the extent to which people process and respond to feedback (Ilgen, Fisher, \& Taylor, 1979). When examining feedback quality, we utilized an intra-individual methodology in which job seekers provided a weekly assessment of feedback quality for the specific companies they received feedback from.

Second, in order to understand why feedback quality is important during job search, we sought to determine its effects on affective, cognitive, and behavioral processes on a weekly basis. In doing so, we developed a conceptual model (see Figure 1) that draws on the feedback literature and recent models of dynamic job search self-regulation (e.g., da Motta Veiga, Turban,

\footnotetext{
${ }^{1}$ Definitions of feedback quality also highlight that feedback should be consistent - that is, the feedback provider (e.g., supervisor) should provide consistent information across time (Dahling et al., 2017; Steelman et al., 2004; Whitaker \& Levy, 2012). Given that our research (a) focused on feedback from an individual with whom job seekers would likely not have repeated contact (e.g., a recruiter), and (b) took a within-person approach that captures intraindividual variability, we focus purely on the informational value and usefulness aspects of this particular feedback environment dimension.
} 
Gabriel, \& Chawla, 2018) to hypothesize that the informational value of high quality feedback triggers increased positive affect and decreased negative affect among job seekers upon receipt (e.g., Weiss \& Cropanzano, 1996). In line with social cognitive theory (Bandura, 1986, 1991), we further posit that positive and negative affect differentially predict subsequent cognitive processes - specifically, metacognitive strategies (e.g., setting/revising job search-related goals; Turban et al., 2009) and affective rumination (i.e., feeling tense and fatigued when thinking about job search-related issues; Querstret \& Cropley, 2012)—associated with job seeking. Additionally, in order to understand how these cognitive processes manifest behaviorally during the job search process, we examine metacognitive strategies and affective rumination as drivers of both job search intensity (i.e., number of résumés submitted weekly; Turban et al., 2009) and job search effort (i.e., number of hours spent job seeking each week; Wanberg et al., 2010).

Third, fitting with broader theorizing surrounding the feedback process (e.g., Chawla, Gabriel, Dahling, \& Patel, 2016; Dahling, Chau, \& O’Malley, 2012), we recognize that not all job seekers may respond to feedback quality similarly. As such, stable, between-person factors may affect weekly dynamics associated with feedback quality during job search (e.g., da Motta Veiga et al., 2018). Because of this, we examine the moderating role of job seekers' feedback self-efficacy in influencing job seekers' reactions to feedback quality on a weekly basis. Feedback self-efficacy refers to the extent to which individuals perceive that they can accurately interpret and appropriately respond to feedback (Linderbaum \& Levy, 2010). Consistent with social cognitive theory (Bandura, 1986, 1991), we theorize that feedback self-efficacy affects the extent to which job seekers are able to successfully process and regulate their reactions in response to the feedback received. More specifically, we theorize that higher levels of feedback self-efficacy serve as a buffer for job seekers, reducing the impact of feedback quality on affect. 
Feedback and Job Search Processes 6

In the sections that follow, we first provide a brief overview of past job search research that has taken a dynamic, self-regulated approach, arguing why this lens is necessary for the current investigation. We then provide an overview of the feedback literature as it pertains to the job search process and the development of our overall conceptual model and hypotheses.

\section{Overview of Job Search Self-Regulation}

From a self-regulatory perspective, the job search is a "purposive, volitional pattern of action that begins with the identification and commitment to pursuing an employment goal" (Kanfer et al., 2001, p. 838). As such, after job seekers begin searching for a job, they must expend effort and engage in behaviors that aid in the pursuit of the desired goal (i.e., obtaining employment). Throughout this volatile process, job seekers continuously evaluate and monitor their progress. Information from the environment that signals job seekers' progress triggers affective and cognitive processes, which serve to cope with discrepancies and guide the adjustment of future search strategies and efforts (Wanberg et al., 2010). Consistent with this, several studies have elucidated the variability in job seekers' cognitive, affective, and behavioral processes over time (e.g., da Motta Veiga \& Turban, 2014; Song, Uy, Zhang, \& Shi, 2009; Sun et al., 2013; Wanberg et al., 2012; Wanberg et al., 2010), illustrating that the job search is indeed a dynamic process warranting examination (da Motta Veiga et al., 2018; Wanberg et al., 2010).

Although self-regulation theories - and social cognitive theory in particular (Bandura, 1986) — note the importance of environmental events in necessitating effective self-regulation, there has been no empirical examination of this relationship in the context of job search. Furthermore, little is known about how affective, cognitive, and behavioral regulatory processes are dynamically linked and how they unfold weekly throughout the job search. This is problematic given that Lord, Diefendorff, Schmidt, and Hall (2010) argue that models of self- 
regulation "must account for the dynamic interrelations between affect and cognition" (p. 547). In sum, although there is little doubt that effective self-regulation is critical to job search success, research has yet to identify the role of job search events in engendering effective self-regulation, and the mechanisms underlying this relationship. Thus, we present a critical antecedent of these processes — feedback quality — and detail how feedback quality should influence these outcomes.

\section{The Role of Feedback Quality in Job Search Self-Regulation}

When considering self-regulation, the role of feedback cannot be denied (Bandura, 1989, 1991). Indeed, one of the initial theories of self-regulation - control theory (Carver \& Scheier, 1981, 1990) - is grounded in the concept of feedback loops, wherein "intentional behavior (reflects) a process of feedback control” (Carver \& Scheier, 1990, p. 19). As noted by other theories of self-regulation, such as social cognitive theory (Bandura, 1989, 1991) and feedback intervention theory (FIT; Kluger \& DeNisi, 1996), feedback provides individuals with information that allows them to compare their current performance against a specific goal. Because self-regulation involves (a) setting goals, (b) detecting discrepancies, and (c) reducing discrepancies via changes in cognitions and behaviors (Ashford \& Tsui, 1991), feedback is essential to effective regulation as it sheds light on the discrepancy between current and desired states. In fact, Bandura (1991) states that feedback is the "basic regulator" (p. 258) in selfregulation theories. This view recognizes that reducing discrepancies necessitates discrepancy detection, which is only possible through feedback-related processes and perceptions.

Job search scholars have often alluded to the notion that feedback provides valuable information to job seekers, prompting adjustment of strategies and goals (Kanfer et al., 2001; Liu et al., 2014; Lopez-Kidwell et al., 2013; Sun et al., 2013; Wanberg et al., 2010). For example, Wanberg et al. (2010) argued that job seekers' perceptions of their (lack of) progress can arise 
from feedback, while Liu et al. (2014) discussed that feedback can impact job search selfefficacy, ultimately influencing search behaviors. Yet, despite the purported role of feedback, research has yet to examine how feedback triggers self-regulatory efforts during job search.

Indeed, although feedback is an inherent component of job search (e.g., receiving interviews, job offers, and rejections), the job search context is unique in that individuals often continuously receive feedback from multiple sources on a regular basis. As an example, a job seeker may receive feedback on his/her fit with the company through an online system one week, and receive feedback on his/her interview from a recruiter the following week. Thus, feedback in the job search context is conceptually and practically distinct from commonly-studied performance appraisals or other organizational contexts wherein feedback is delivered by the same source with whom the recipient has an ongoing relationship (Steelman et al., 2004). In line with this idea, Nathan, Mohrman, and Milliman (1991) found that employees' satisfaction with feedback received during performance appraisal positively correlated with the interpersonal relationship between the supervisor delivering the feedback and the supervisee receiving it.

Absent of this relational component of feedback in the job search context, we contend that the informational value of the feedback received — in terms of its ability to accurately detect shortcomings and guide future behavior-is of critical importance to job seekers as they attempt to regulate search strategies to secure employment. For example, a generic rejection email sent to applicants has lower value in terms of helping a job seeker tailor future applications compared to a rejection with feedback that explains why an applicant was rejected. According to FIT (Kluger \& DeNisi, 1996), feedback that does not provide information regarding the effectiveness of one's current strategies, appropriate task behaviors, and/or possible solutions is less useful because it directs attention toward the self rather than toward task-motivation or task-learning processes. In 
contrast, feedback with high quality information on goal-directed processes and behaviors likely includes diagnostic information on task-related errors and/or opportunities for growth, increasing resources toward the task (i.e., securing a job; Kanfer \& Ackerman, 1989; Kluger \& DeNisi, 1996). Consistent with this, Bandura (1991) noted the criticality of the 'informativeness' of feedback in helping people accurately determine the effectiveness of their strategies, influencing the success of subsequent regulatory efforts. As such, in the sections that follow, we theorize that feedback quality — how useful and valuable the feedback received is - may serve as an important feedback event during job search yielding critical regulatory consequences for job seekers.

\section{Feedback Quality and Affective Reactions}

According to FIT (Kluger \& DeNisi, 1996), feedback events are affect-laden experiences, particularly those that prompt cognitive appraisals regarding one's performance relative to an important goal (e.g., receiving a job offer). Consistent with this, affective events theory (AET; Weiss \& Cropanzano, 1996) also positions the receipt of feedback as an event that impacts recipients' affective states (Ilies \& Judge, 2005). Indeed, scholars have drawn upon AET to demonstrate that feedback is an affective event that influences recipients' attitudes and behaviors through its impact on their affect (e.g., Ilies \& Judge, 2005; Ilies, De Pater, \& Judge, 2007; Lam, Yik, \& Schaubroeck, 2002). However, affective reactions to feedback can be influenced by several factors, such as the extent to which the feedback yields informational value (Elicker, Levy, \& Hall, 2006; Kluger \& DeNisi, 1996; Steelman et al., 2004), or is of high quality. Feedback quality represents one facet of the feedback environment, a model of feedback capturing contextual aspects of informal day-to-day feedback exchanges between employees and both their supervisors and coworkers (Steelman et al., 2004). The feedback environment encompasses seven dimensions: (a) feedback quality (i.e., perceived value/utility of the 
feedback); (b) source credibility (i.e., judgments about the qualification of the feedback source);

(c) feedback delivery (i.e., how considerately feedback is delivered); (d) frequency of favorable feedback (i.e., receipt of positive feedback when warranted); (e) frequency of unfavorable feedback (i.e., receipt of negative feedback when warranted); (f) source availability (i.e., regular access to feedback); and (g) promotion of feedback seeking (i.e., active encouragement and support for employee seeking of feedback; Chawla et al., 2016; Steelman et al., 2004). In delineating the most theoretically applicable dimension to job search, we focused on feedback quality for two key reasons. First, job seekers prototypically receive feedback from sources likely unknown to them and/or sources who are not likely to be daily exchange partners at work that would facilitate the other feedback environment dimensions (e.g., a recruiter; Chawla et al., 2016; Wang et al., 2015). Second, and as mentioned above, the 'informativeness' of feedbackcaptured through feedback quality (Steelman et al., 2004)—plays a crucial role in regulating efforts toward successful goal accomplishment (i.e., obtaining a job; Bandura, 1991; Whitaker \& Levy, 2012) $)^{2}$.

High quality feedback is typically perceived as more useful compared to low quality feedback as it has greater informational value in terms of its relevance, specificity, and detail (Steelman et al., 2004; Wang et al., 2015). This informational value of feedback—and, therefore, the feedback quality—is "assessed from the recipient's point of view" (Steelman et al., 2004, p. 167), capturing the extent to which the feedback is perceived as helpful by the job seeker. High quality feedback provides the recipient with cues that signal the adequacy of current strategies

\footnotetext{
${ }^{2}$ We acknowledge that we are isolating one aspect of feedback — feedback quality — when considering affective reactions during job search, despite the fact that feedback may be multifaceted and varying in valence. Importantly, we theorize that feedback quality is of critical value to job seekers regardless of the valence of the feedback as it provides greater direction regarding the manner in which search strategies and effort need to be regulated. Nevertheless, we conducted supplemental analyses (see below) to provide greater support for this assertion.
} 
and/or how future behavior needs to be regulated. Accordingly, high quality feedback, rather than low quality feedback, can help job seekers improve their job search performance and achieve the ultimate goal of securing a job. Consistent with this, research shows that individuals' evaluations of feedback hinge on its informational value: recipients are more likely to accept feedback that is specific versus vague in nature (Ilgen et al., 1979), and relevant, detailed feedback is perceived as more valuable (Brett \& Atwater, 2001). With high quality feedback perceived as being "more useful and accurate" (p. 1300), it is associated with more favorable reactions and greater satisfaction, compared to low quality feedback (Wang et al., 2015). In fact, the quality of the feedback improves recipients' reactions to feedback regardless of its favorability, with Steelman and Rutkowski (2004) finding that feedback quality was associated with greater satisfaction despite the negative information being conveyed in the feedback.

In line with this, we theorize that job seekers' affective reactions are contingent upon the extent to which they perceive the feedback they received as valuable in helping them assess the effectiveness of their current strategies and/or how future search efforts need to be regulated (see also Endler \& Magnusson, 1976), positioning feedback quality as a salient affective event (Weiss \& Cropanzano, 1996). More specifically, we theorize that higher levels of feedback quality will relate positively to positive affect during job search, as high quality feedback will provide job seekers with more useful and accurate guidance on the effectiveness of their current search strategies and how to proceed with their search efforts (e.g., Wang et al., 2015). Conversely, low quality feedback is likely to be distressing and frustrating as it lacks informational value regarding the extent to which self-regulatory efforts are required and/or need to be revised. This heightened lack of clarity should translate to increased negative affect on a weekly basis. Taken together, we hypothesize the following relationships: 
Feedback and Job Search Processes 12

Hypothesis 1: On a weekly basis, feedback quality is (a) positively related to positive affect and (b) negatively related to negative affect.

Individual dispositions, however, may play an important role in determining job seekers' affective reactions to feedback quality (Kluger \& DeNisi, 1996). While several individual differences have been considered in relation to feedback experiences (e.g., goal orientation; VandeWalle, Cron, \& Slocum, 2001; age; Wang et al., 2015), we theorize that feedback selfefficacy is a critical moderator, owing to the fact that self-efficacy is a key determinant of selfregulation following external events or cues from the environment (Bandura, 1986, 1991; Bandura, \& Locke, 2003). In considering self-efficacy more generally, scholars have noted that individuals with higher levels of self-efficacy are more likely to seek feedback about themselves (Anseel, Beatty, Shen, Lievens, \& Sackett, 2015) and are less threatened by feedback (Ashford, 1986), likely because they view the information obtained to be useful regardless of the characteristics (e.g., quality) of the feedback message itself. Indeed, individuals with higher selfefficacy experience fewer negative emotions during stressful situations, thus coping better with the feedback event and focusing on opportunities (rather than obstacles) presented by the feedback (Jerusalem \& Schwarzer, 1992; Luszczynska, Scholz, \& Schwarzer, 2005).

Although prior research has largely focused on generalized self-efficacy that captures individuals' beliefs regarding their competency to effectively handle a variety of situations across domains, Linderbaum and Levy (2010) introduced feedback self-efficacy to refer specifically to feedback recipients" "perceived competence to interpret and respond to feedback appropriately" (p. 1378). Thus, consistent with research on self-efficacy in general (Jerusalem \& Schwarzer, 1992; Jex \& Bliese, 1999), we theorize that feedback self-efficacy is an important personal resource that influences affective reactions tied to feedback experiences. 
Higher feedback self-efficacy is associated with both satisfaction and perceptions of utility of the performance appraisal session (Linderbaum \& Levy, 2010), because greater confidence in dealing with feedback allows recipients to use it more effectively. To the extent that individuals (i.e., job seekers) with higher feedback self-efficacy are generally self-assured in their ability to deal with and utilize feedback (Linderbaum \& Levy, 2010), the quality of the feedback received on a weekly basis should be less critical for these job seekers. Higher feedback self-efficacy likely allows job seekers to make the most of the feedback that has been offered, regardless of the level of feedback quality received. Given this, positive and negative affective reactions to feedback quality are likely also weaker among job seekers with higher feedback self-efficacy, as trait self-efficacy acts as a general buffer.

On the other hand, individuals with lower self-efficacy experience anxiety and distress, and are more prone to self-doubts (Jerusalem \& Schwarzer, 1992). Hence, less efficacious individuals engage in fewer coping efforts (Gist, 1987), instead becoming more reactive to their personal deficiencies (Strecher, McEvoy DeVellis, Becker, \& Rosenstock, 1986). Applying these ideas to the job search context, the characteristics of the feedback message should be more critical for job seekers who have lower feedback self-efficacy, as these individuals require greater clarity surrounding the manner in which the feedback should be dealt with. With respect to feedback quality in particular, feedback of informational value is more directive, providing greater detail on how future behavior can be regulated more effectively and, simultaneously, shifting undue attention away from self-doubts. Conversely, feedback lacking in informational value provides little guidance on the extent to which job seekers' current search strategies are (in)effective and/or how they can improve, which should be particularly detrimental for job seekers with lower feedback self-efficacy given their lack of confidence in responding to 
Feedback and Job Search Processes 14

feedback. These arguments are consistent with behavioral plasticity theory (Brockner, 1983, 1998), which suggests that individuals with lower self-efficacy are generally more susceptible and reactive to external sociocontextual cues (e.g., feedback quality) compared to individuals with higher self-efficacy. As such, we contend that lower self-efficacy in a given domain (e.g., feedback) makes individuals more 'behaviorally plastic' (Brockner, 1988; Pierce, Gardner, Dunham, \& Cummings, 1993) and, thus, more reactive to the informational value of a feedback event. Taken together, we expect that the relationship between feedback quality and both affective reactions will be stronger for job seekers with lower levels of feedback self-efficacy.

Hypothesis 2: Feedback self-efficacy moderates the weekly relationships between feedback quality and (a) positive affect and (b) negative affect; the relationships are stronger for job seekers with lower feedback self-efficacy than for those with higher feedback self-efficacy.

\section{Affective Reactions and Job Search Processes}

When considering the role of affect during self-regulation, scholars have invoked social cognitive theory, which suggests that affective self-reactions serve to enhance motivation (Bandura, 1991) and drive conscious attention (Seo, Barrett, \& Bartunek, 2004). This, in turn, impacts individuals' cognitive processes and decision-making, ultimately influencing goaldirected behaviors (Seo et al., 2004). More specifically, social cognitive theory suggests that during complex tasks such as securing a job, positive affect (i.e., self-satisfaction) signals success, thereby motivating individuals to persist and further exert effort toward goal-directed behaviors (Bandura, 1986, 1991). In fact, according to this view, positive affect can reinforce confidence to such a degree that it often results in individuals revising and setting more challenging goals for themselves (Ilies \& Judge, 2005). On the other hand, negative affect (i.e., 
self-dissatisfaction) signals that the current course of action is failing (Bandura, 1986). As such, negative affect is demotivating, causing individuals to reduce their goal-directed efforts and withdraw from the task at hand (Bandura, 1991). In the present study, we expand upon prior research in adopting this theoretical lens to explore how positive and negative affect relate differentially to both effective and ineffective cognitive regulatory processes.

With respect to effective cognitive regulatory processes, job search scholars have often emphasized the critical—and beneficial—role of metacognitive strategies, particularly for new labor market entrants who are navigating the complex, unstructured, and relatively uncertain process that is job seeking for the first time (da Motta Veiga \& Gabriel, 2016; Koen, van Vianen, van Hooft, \& Klehe, 2016; Turban et al., 2009). Metacognitive strategies represent the extent to which job seekers develop job search plans, set and revise personal goals, monitor the environment for cues regarding progress, analyze the effectiveness of their strategies, and continuously improve their job search skills (Turban et al., 2009). Thus, metacognitive strategies capture job seekers' abilities to continuously reflect on and learn from their job search experiences (Turban et al., 2009), and the extent to which they maintain focus toward their employment goals throughout the job search (da Motta Veiga \& Gabriel, 2016).

Because job seekers view employment goals as highly important and complex, their persistence toward employment goals should increase when they experience positive affect. This theorizing is consistent with social cognitive theory (Bandura, 1986, 1991), which posits that positive affect signals that things are going well, encouraging individuals to envision and anticipate future outcomes, subsequently boosting efforts that increase the likelihood of reaching those goals (Foo, Uy, \& Baron, 2009). Additionally, although not explicitly concerned with selfregulation, this view of positive affect is also consistent with broaden-and-build theory 
Feedback and Job Search Processes 16

(Fredrickson, 1998, 2001), which contends that positive affect builds personal resources and broadens momentary thought-action repertoires. In support of these ideas, research has found that positive affect increases intrinsic motivation (Isen \& Reeve, 2005), promotes the extent to which individuals set and revise challenging goals (Ilies \& Judge, 2005; Parker, Bindl, \& Strauss, 2010), and fosters approach-oriented behavior (Cacioppo, Gardner, \& Berntson, 1999). The cognitive broadening and flexibility that accompany positive affect also facilitates effective problem solving and increased creative thinking, especially when obstacles arise during goal striving (Isen, 1987, 1993; Parker et al., 2010). In the context of the job search, these selfregulatory effects of positive affect are consistent with the core features of metacognitive strategies. Therefore, we expect that when job seekers experience positive affect as a result of high quality feedback, they will engage in more metacognitive strategizing.

On the other hand, when job seekers receive low quality feedback, leading to increased negative affect, metacognitive strategizing likely decreases. Social cognitive theory posits that negative affect is demotivating, leading to reduced effort toward goal accomplishment (Bandura, 1986, 1991). Additionally, during situations of uncertainty (e.g., a lack of knowledge surrounding the effectiveness of one's job search strategies), negative emotions, like anxiety, generate avoidance tendencies (Lazarus, 1991). Consistent with this, Wanberg et al. (2010) found that some job seekers reported the need to take time off, as the negative affect that arose from lower perceived progress was too discouraging. Importantly, social cognitive theory contends that negative self-reactions, such as negative affect (Wanberg et al., 2010), impair goaldirected efforts because they prevent individuals from "generating and testing alternative strategies of action" (Bandura, 1991, p. 263), which is essential to using metacognitive strategies. Given these properties, negative affect also has the potential to trigger ineffective 
cognitive processes, such as affective rumination (Meier, Gross, Spector, \& Semmer, 2013;

Moberly \& Watkins, 2010). Affective rumination refers to the presence of intrusive, pervasive, and recurrent negative thoughts about recent events, one's current mood state, or one's failure to achieve goals (Cropley \& Zijlstra, 2011; Cropley, Michalianou, Pravettoni, \& Millward, 2012; Pravettoni, Cropley, Leotta, \& Bagnara, 2007). Specifically, Martin and Tesser (1996) suggest that negative affect increases rumination because it signals difficulties surrounding goal attainment (i.e., ruminating and focusing on one's failures). For example, through an experience sampling study, Moberly and Watkins (2010) found that individuals engage in greater affective rumination when they are unable to achieve their goals due to increased negative affect. Conversely, as positive affect signals success with one's strategies (Bandura, 1986, 1991), job seekers' experiences of positive affect should decrease perceptions of threat in the environment (i.e., one is not at risk of not obtaining job search success). As such, affective rumination should be reduced when job seekers experience positive affect (Martin \& Tesser, 1996). Consistent with these ideas, the elicitation of positive affect during stressful situations, such as the job search, can short-circuit and diminish an affective rumination spiral (Folkman \& Moskowitz, 2000).

Taken together, we posit that job seekers' experiences of positive affect prompt effective weekly cognitive self-regulation (i.e., increased metacognitive strategies, decreased affective rumination), whereas negative affect prompts ineffective weekly cognitive self-regulation (i.e., increased affective rumination, decreased metacognitive strategies). Thus, we hypothesize:

Hypothesis 3: On a weekly basis, (a) positive affect is positively related to metacognitive strategies, and (b) negative affect is negatively related to metacognitive strategies.

Hypothesis 4: On a weekly basis, (a) positive affect is negatively related to affective rumination, and (b) negative affect is positively related to affective rumination. 
Feedback and Job Search Processes 18

Finally, both metacognitive strategies and affective rumination should impact job search behaviors; in the current study, we focused on both job search intensity and job search effort (e.g., Saks, 2005; Turban et al., 2009; Wanberg et al., 2010). While job search intensity reflects the frequency with which job seekers engage in specific job search activities (e.g., sending résumés), job search effort captures the "amount of energy, time, and persistence that a job seeker devotes to his or her job search" (Saks, 2005, p. 160) more generally. Although both job search intensity and effort encompass behaviors directed toward securing employment, they are distinct constructs (Saks, 2005) and have been studied as such. Following recommendations and prior work on these behavioral criteria (e.g., Saks, 2006; Wanberg, 2012; Wanberg et al., 2010), we used the number of résumés sent each week as an indicator of job search intensity, and the number of hours spent job seeking each week as an indicator of job search effort.

As metacognitive strategies refer to developing job search plans, adjusting goals, and improving job search skills (Turban et al., 2009), it should be associated with the expenditure of both intensity and effort devoted to job search activities. Indeed, in a weekly study of job seekers, da Motta Veiga and Gabriel (2016) found that metacognitive strategies were positively associated with greater perceived job search effort. Similarly, in considering the number of résumés sent as an indicator of job search intensity, Turban et al. (2009) found in their personlevel study that metacognitive strategies positively predicted the number of résumés sent. As such, we expect that job seekers' metacognitive strategies will positively predict both (a) the number of résumés sent, and (b) the number of hours spent job seeking each week.

In contrast, affective rumination is likely detrimental to job seeking as it is characterized by uncontrollable and repetitive thoughts about a distressful situation (e.g., receiving low quality feedback), its possible causes (e.g., lack of qualifications), and its potential consequences (e.g., 
failure to secure a job). As such, affective rumination reinforces and exacerbates negative emotions, prolonging distress and increasing fatigue (Denson, Fabiansson, Creswell, \& Pedersen, 2009; Nolen-Hoeksema, Wisco, \& Lyubomirsky, 2008; Wang et al., 2011); thus, it has often been associated with maladaptive coping responses and reduced cognitive skills (Denson et al., 2009; Webb, Miles, \& Sheeran, 2012). These effects are likely due to the fact that affective rumination involves a fixation on the problem and the emotions elicited, rather than on behaviors directed toward active and effective problem solving (Nolen-Hoeksema et al., 2008). This body of work suggests that when job seekers ruminate about the job search, they will (a) send out fewer résumés, and (b) spend less time engaging in job search activities. Therefore, we predict: Hypothesis 5: On a weekly basis, metacognitive strategies are positively related to (a) the number of résumés sent, and (b) the number of hours spent job seeking. Hypothesis 6: On a weekly basis, affective rumination is negatively related to (a) the number of résumés sent, and (b) the number of hours spent job seeking. In sum, Hypotheses 1 through 6 suggest moderated mediation, such that the indirect effect of job search feedback quality on job search behaviors (i.e., the number of résumés sent and the number of hours spent job seeking) is serially mediated via affective and cognitive processes, with the effects being stronger for job seekers with lower, versus higher, feedback self-efficacy (see Figure 1). As such, we make the following series of predictions:

Hypothesis 7: Feedback self-efficacy moderates the serial indirect effects of feedback quality on (a) the number of résumés sent, and (b) the number of hours spent job seeking via positive affect and metacognitive strategies; the effects are stronger for job seekers with lower (vs. higher) feedback self-efficacy.

Hypothesis 8: Feedback self-efficacy moderates the serial indirect effects of feedback 
Feedback and Job Search Processes 20

quality on (a) the number of résumés sent, and (b) the number of hours spent job seeking via negative affect and metacognitive strategies; the effects are stronger for job seekers with lower (vs. higher) feedback self-efficacy.

Hypothesis 9: Feedback self-efficacy moderates the serial indirect effects of feedback quality on (a) the number of résumés sent, and (b) the number of hours spent job seeking via positive affect and affective rumination; the effects are stronger for job seekers with lower (vs. higher) feedback self-efficacy.

Hypothesis 10: Feedback self-efficacy moderates the serial indirect effects of feedback quality on (a) the number of résumés sent, and (b) the number of hours spent job seeking via negative affect and affective rumination; the effects are stronger for job seekers with lower (vs. higher) feedback self-efficacy.

\section{Method}

\section{Participants and Procedure}

Our sample of new labor market entrants consisted of undergraduate business school students at a large Southwestern U.S. university who were actively seeking jobs. Specifically, students were offered the opportunity to participate in a weekly study about their experiences during their job search in exchange for course extra credit and the opportunity to win one of four $\$ 100$ gift cards. Students who indicated interest were sent an introductory email that outlined the purpose of the study and the link to an opt-in survey; the opt-in survey included measures assessing their feedback self-efficacy and demographics, as well as the nature of their job search (i.e., seeking a full-time job versus a full-time internship). In total, 439 students received the introductory email, of whom 242 were actively job seeking and completed the opt-in survey. After the opt-in survey was completed, participants received an email Thursday morning 
each week for seven weeks. We began our weekly surveys at the time of an on-campus career fair, as this was a critical temporal landmark that is typically viewed as the start of the job search cycle (e.g., da Motta Veiga \& Gabriel, 2016). Moreover, we continued the surveys for the remainder of the academic semester or until participants indicated they were no longer seeking employment. Participants were required to complete each weekly survey by Sunday night; reminders were sent via email on Friday and Sunday mornings to increase response rates. We selected a weekly survey in order to allow enough time for our focal constructs to vary, as it is unlikely that job seekers are receiving feedback on their job applications on a daily basis (e.g., Ebner-Priemer \& Trull, 2011). Moreover, prior job search research has noted that the ideal time frame should depend on the study's goals and temporal dynamics underlying the constructs of interest (e.g., da Motta Veiga \& Gabriel, 2016; da Motta Veiga \& Turban, 2014).

Of the 242 eligible participants, 93 received feedback during at least three weeks of the study and comprised our final sample; having three weekly (Level 1) data points is statistically necessary in order to appropriately model within-person relationships. Moreover, having at least three data points per person helps ensure that we reasonably captured the "lived" experience of job seekers (e.g., Weiss \& Rupp, 2011). The 93 participants provided 394 weekly surveys, yielding an average of 4.24 surveys per person; 651 weekly surveys were possible, yielding a response rate of $60.5 \%$. Our sample was mostly female $(54.8 \%)$ and white $(60.2 \%)$. Participants were 22.43 years of age on average $(S D=3.24$; range $=20-38)$ with an average GPA of 3.27 out of $4.00(S D=0.34$; range $=2.50-3.97)$, which approximates the national average (Rojstaczer, 2009) and is consistent with prior job search research (e.g., da Motta Veiga \& Gabriel, 2016; Liu et al., 2014; Turban, Lee, da Motta Veiga, Haggard, \& Wu, 2013).

\section{Opt-In (Between-Person) Survey Measure (Level 2)}


Feedback self-efficacy. We used five items adapted from Linderbaum and Levy (2010). Participants were asked to think about receiving feedback during the job search process and rate the extent to which they agreed or disagree with each item in general on a 5 -point scale $(1=$ strongly disagree; 5 = strongly agree). The items were: "I believe that I will have the ability to deal with feedback during the job/internship search effectively;" "I will feel self-assured when dealing with feedback during the job/internship search;" "Compared to others, I will be more competent at handling feedback during the job/internship search;" "I will feel confident when responding to both positive and negative feedback during the job/internship search;" and "I know that I will be able to handle the feedback that I receive during the job/internship search."

\section{Weekly (Within-Person) Survey Measures (Level 1)}

Feedback quality. At the beginning of each weekly survey, participants indicated whether they received feedback about their job search during the past week. Feedback referred to any information pertaining to the job/internship process, including feedback on the applicant's application, an interview offer, or a job offer. Participants were presented with a list of types of feedback, and were asked to check all that applied ${ }^{3}$. If participants indicated that they had received at least one type of feedback, they then indicated the number of companies from which they received feedback. Following this, participants provided the name of each company they had received feedback from (e.g., if ' 3 ' was selected for the number of companies feedback was received from, three spaces appeared to enter each company name). We then presented participants with the name of a company they received feedback from, asking them to reflect on the feedback they received from that specific company and describe how they reacted to it. Following this, job seekers made assessments of the quality of the feedback received.

\footnotetext{
${ }^{3}$ Participants who indicated that they did not receive feedback during a given week were not presented with the feedback quality measure; they proceeded to complete the affective, cognitive strategies, and behavioral measures.
} 
Importantly, if participants received feedback from multiple companies, we designed the survey such that three companies were randomly selected, and assessments of feedback quality were made with reference to the selected companies. We did so for two reasons. First, if participants received feedback from multiple companies, randomly selecting only one company would be problematic as participants' affective and cognitive responses are likely impacted by their combined feedback experiences. For example, a job seeker's affective reactions will likely be different if he/she received high quality feedback from one company and low quality feedback from another company on a given week, compared to high quality feedback from two companies. However, we did not want participants to mentally aggregate feedback quality ratings across multiple companies (e.g., high and low quality experiences) due to the potential biases that this could cause (Robinson \& Clore, 2002). As such, providing ratings per each of the three randomly presented companies allowed participants to rate each distinct feedback quality experience. Second, although we wanted feedback quality ratings to be made with reference to specific companies, we wished to avoid participant fatigue that could result from rating each and every feedback experience (cf. Beal, 2015). To ensure that this decision to limit to three companies per week was justified, we assessed the number of organizations job seekers were receiving feedback from on a weekly basis. Across the seven weeks, the majority of job seekers included in our final dataset received feedback from three companies or less (77.4\%). Stated differently, of the 394 weekly feedback experiences, 370 (93.9\%) were a result of feedback received from three companies or less, and $263(66.8 \%)$ were a result of feedback received from one company only. Nevertheless, we considered the effects of the number of organizations participants received feedback on our results (see Control Variables below).

In order to fit within the broader feedback literature, we assessed feedback quality with 
Feedback and Job Search Processes 24

three items modified from Steelman et al.'s (2004) original feedback environment scale. To draw attention to each specific feedback event, participants were given the following instructions: "Thinking back to the feedback you received about your job/internship search this week from [company name here in bold], please indicate the extent to which you agree or disagree with the following statements." The items rated on a 5-point scale $(1=$ strongly disagree; $5=$ strongly agree) were: "The feedback I received this week was useful;" "I value the feedback I received this week;" and "The feedback I received this week will help me in the job/internship search process." Thus, consistent with the original conceptualization by Steelman et al. (2004) and in line with prior work on feedback quality (e.g., Allen, Shockley, \& Poteat, 2010; Rosen, Levy, \& Hall, 2006; Sparr \& Sonnentag, 2008; Steelman \& Rutkowski, 2004; Wang et al., 2015; Whitaker \& Levy, 2012), our measure captured recipients' perceptions of the informational value of the feedback, rather than the characteristics of the message itself. For participants who received feedback from multiple companies, we averaged quality ratings across companies. This decision conceptually aligned with our affective, cognitive, and behavioral measures that were broadly focused on the entire week of job seeking (however, see Supplemental Analysis for an alternative way of analyzing the feedback quality data in which results remain the same).

Affect. We assessed positive and negative affect with four items each from the JobRelated Affective Well-Being Scale (Van Katwyk, Fox, Spector, \& Kelloway, 2000; see also Gabriel, Diefendorff, Chandler, Moran, \& Greguras, 2014; Yang \& Diefendorff, 2009). Participants assessed how they felt that week about their job/internship search on a 5-point scale $(1$ = strongly disagree $; 5=$ strongly agree $)$. Example positive affect items were "enthusiastic" and "energetic;" example negative affect items were "anxious" and "frustrated."

Metacognitive strategies. We used six items adapted from Turban et al. (2009; see da 
Motta Veiga \& Gabriel, 2016). Participants rated the extent to which they engaged in each job search-related behavior during the past week on a 5-point scale $(1=$ I never did or thought this; 5 =I did or thought this all the time): "set personal goals to help guide job/internship search activities;" "developed a coherent plan to guide my job/internship search;" "monitored my progress toward finding a job/internship;" "thought about how best to present myself to potential employers;" "analyzed interviews to improve subsequent performance;" and "thought about how to improve my skills at finding a job."

Affective rumination. We measured affective rumination with four items adapted from Cropley et al. (2012). Participants rated the extent to which they engaged in each item during the past week on a 5-point scale ( 1 = strongly disagree; 5 = strongly agree $)$. The items were: "I became tense when thinking about job/internship search-related issues;" "I became irritated by job/internship search-related issues;" "I became fatigued thinking about job/internship searchrelated issues;" and "I was troubled by job/internship search-related issues."

Résumés. We used a single item asking participants to indicate the number of résumés they had submitted during the past week: "How many résumés did you send out this week?"

Job seeking hours. Consistent with prior research (e.g., Wanberg et al., 2010), we assessed the amount of time participants spent engaging in job search activities each week using a single item: "In the past week, approximately how many hours did you devote to your job/internship search? Please round up to the nearest hour (e.g., 2.5 hours $=3$ hours).”

\section{Control Variables}

Based on prior job search research (e.g., da Motta Veiga \& Gabriel, 2016; Turban et al., 2013; Turban et al., 2009), we controlled for gender and GPA in our analyses at Level 2 (i.e., the between-person level of analysis). Additionally, given that some of our participants were making 
Feedback and Job Search Processes 26

feedback quality ratings for multiple companies, we controlled for the number of organizations participants received feedback from at Level 1 (i.e., the within-person level of analysis). Finally, to help eliminate spurious effects due to time (e.g., Beal \& Weiss, 2003), we also modeled week of the study (i.e., Week 1-7) on all Level 1 paths. Including these control variables did not alter our findings; that is, all relationships remained qualitatively the same. As such, we elected not to include them in our final model test (Spector \& Brannick, 2010). That said, we do present the within- and between-person correlations of all of our control variables in Table 1.

\section{Analytic Approach}

Given that our weekly surveys were nested within-person, we used multilevel path analysis in MPlus 7.4 (Muthén \& Muthén, 1998-2013). To ensure that multilevel analyses were warranted, we first ran a series of null models and found substantial within-person variance in our focal study constructs (feedback quality: 65.79\%; positive affect: 56.84\%; negative affect: 50.13\%; metacognitive strategies: $45.58 \%$; affective rumination: $45.87 \%$; résumés sent: $85.67 \%$; job seeking hours: $80.75 \%$ ). We also performed a multilevel CFA that tested the hypothesized six-factor structure, excluding résumés and hours spent job seeking, given that these were single item measures. We modeled our five within-person variables (feedback quality, positive affect, negative affect, metacognitive strategies, and affective rumination) and our between-person variable (feedback self-efficacy). Following Scott, Colquitt, Paddock, and Judge (2010), the Level 1 items were centered relative to each participant's mean item score and the Level 2 items were centered relative to the sample mean. Given that we had multiple ratings of companies for our three feedback quality items, we used the ratings from the first company for our multilevel CFA; this made statistical sense, as all participants reported feedback from at least one company, but not all participants provided ratings of additional companies beyond that. We found that our 
model exhibited good fit to the data $\left(\chi_{(184)}^{2}=286.019, \mathrm{CFI}=.95, \mathrm{RMSEA}=.04, \mathrm{SRMR}_{\mathrm{within}}=\right.$ $\left..05, \mathrm{SRMR}_{\text {between }}=.08\right)^{4}$. Thus, we proceeded with our hypothesis testing.

Following recommendations, Level 1 predictor variables were centered within-person (Enders \& Tofighi, 2007; Hofmann, Griffin, \& Gavin, 2000); this eliminates issues attributable to between-person factors (e.g., response styles, social desirability effects; Enders \& Tofighi, 2007; Gabriel et al., in press), thereby allowing for unbiased estimates of the average withinperson effects at Level 1 (Enders \& Tofighi, 2007; Hofmann, Griffin, \& Gavin, 2000). Our Level 2 moderator, feedback self-efficacy, was grand-mean centered (Enders \& Tofighi, 2007). Following past recommendations (Kline, 2005; Preacher \& Hayes, 2008), residuals for positive and negative affect, metacognitive strategies and affective rumination, as well as number of résumés sent and hours spent job seeking, were allowed to co-vary in order to ensure that the model would not be misspecified, which would result in biased standard errors.

In order to better tease apart causality when examining the downstream effects of feedback quality, and account for common method biases (e.g., Podsakoff, MacKenzie, Lee, \& Podsakoff, 2003), we temporally separated our constructs. We modeled feedback quality and affect at $t$, and cognitive processes (i.e., metacognitive strategies, affective rumination) and behavioral criteria (i.e., number of résumés sent and hours spent job seeking) at $t+1$ (i.e., the next consecutive week of the job search); this mirrors past research focusing on how affective processes tied to job search influence subsequent (i.e., next week) cognitive and behavioral processes (e.g., Wanberg et al., 2010). To provide further support for causality and capture

\footnotetext{
${ }^{4}$ We tested two alternative models. First, we examined a model where we collapsed positive and negative affect into a single factor (modeling four factors instead of five); this model exhibited worse fit $\left(\chi^{2}(188)=422.801, \mathrm{CFI}=.89\right.$, $\mathrm{RMSEA}=.06, \mathrm{SRMR}_{\text {within }}=.07, \mathrm{SRMR}_{\text {between }}=.08$ ). Second, we examined a model that collapsed metacognitive strategies and affective rumination into a single factor (modeling four factors instead of five); this model also demonstrated worse statistical fit $\left(\chi_{(188)}^{2}=558.546, \mathrm{CFI}=.83 ; \mathrm{RMSEA}=.07, \mathrm{SRMR}_{\text {within }}=.10, \mathrm{SRMR}_{\text {between }}=.08\right)$.
} 
Feedback and Job Search Processes 28

change in levels of cognitive processes and behavioral outcomes from one week to the next, we controlled for the prior week's metacognitive strategies, affective rumination, number of résumés sent, and hours spent job seeking at $t$ (Gabriel, Koopman, Rosen, \& Johnson, 2018; Koopman, Lanaj, \& Scott, 2016; Lanaj, Johnson, \& Lee, 2016). Further, consistent with guidelines for mediation (Preacher \& Hayes, 2004, 2008), all possible direct effects were modeled. Following past intra-individual work, these additional variables at Level 1 (i.e., cognitive and behavioral processes at $t$; direct effects) were modeled as fixed to reduce model complexity (Lanaj, Johnson, \& Wang, 2016; Wang, Liu, Liao, Gong, Kammeyer-Mueller, \& Shi, 2013). To test multilevel moderated mediation (Hypotheses 7-10), we utilized a Monte Carlo bootstrap simulation with 20,000 replications to create our bias-corrected 95\% confidence intervals (CI) around each indirect and conditional indirect effects at high and low levels (+/- $1 S D)$ of our moderator (e.g., Koopman, Howe, \& Hollenbeck, 2014; Koopman et al., 2016; Uy, Lin, \& Ilies, 2017).

\section{Results}

Means, standard deviations, reliabilities, and correlations are in Table 1, with results of our multilevel path analysis presented in Table 2 (see also Figure 1). Hypothesis 1 predicted that feedback quality on a weekly basis would be (a) positively related to positive affect and (b) negatively related to negative affect. Results supported these predictions: when job seekers received feedback of high quality during a certain week, they experienced higher positive affect $(\gamma=.51, p<.01)$ and lower negative affect $(\gamma=-.23, p<.01)$. Further, Hypothesis 2 predicted that feedback self-efficacy would moderate the aforementioned relationships, such that the weekly relation between feedback quality and (a) positive and (b) negative affect would be stronger for those with lower feedback self-efficacy. As indicated in Table 2, feedback selfefficacy did not moderate the relation between feedback quality and positive affect $(\gamma=-.19, n s)$; 
thus, Hypothesis 2a was not supported. However, feedback self-efficacy did moderate the relation between feedback quality and negative affect $(\gamma=.33, p<.05)$. As shown in Figure 2, the negative relationship between feedback quality and negative affect was stronger for job seekers with lower feedback self-efficacy (simple slope: $\gamma=-.39, t=-3.42, p<.01$ ) compared to those with higher self-efficacy $(\gamma=-.08, t=-.81, n s)$ supporting Hypothesis $2 \mathrm{~b}$.

Hypotheses 3 and 4 focused on affect predicting cognitive processes; as previously noted, cognitive processes were modeled in the subsequent week. For Hypothesis 3: (a) experiencing positive affect on a weekly basis positively predicted metacognitive strategies $(\gamma=.23, p<.01)$, but (b) weekly negative affect did not $(\gamma=-.03, n s)$. Thus, Hypothesis 3a was supported, but not Hypothesis $3 b$. However, Hypothesis 4 was fully supported: (a) experiencing positive affect weekly subsequently decreased affective rumination $(\gamma=-.17, p<.05)$, while (b) experiencing negative affect weekly subsequently increased affective rumination $(\gamma=.46, p<.01)$.

Linking cognitive processes to behavioral outcomes, Hypothesis 5 predicted that weekly metacognitive strategies would be positively related to (a) the number of résumés sent and (b) the number of hours spent job seeking. Results were supportive: engaging in metacognitive strategies resulted in a higher number of résumés sent $(\gamma=.49, p<.05)$ and hours spent doing job search activities $(\gamma=1.12, p<.01)$. Hypothesis 6 , however, was not supported: affective rumination did not exhibit the anticipated negative relationship with (a) number of résumés sent ( $\gamma=.14, n s)$ nor (b) job seeking hours $(\gamma=.09, n s)$ on a weekly basis.

Finally, Hypotheses 7 through 10 predicted serial moderated mediation for the effect of feedback quality on (a) the number of résumés sent and (b) the numbers of job seeking hours. Given that we did not find all possible main and moderating effects proposed in Hypotheses 1 through 6 (e.g., a non-significant interaction between feedback quality and feedback self-efficacy 
predicting positive affect; a non-significant effect of negative affect predicting metacognitive strategies; a non-significant effect of affective rumination predicting number of résumés sent; a non-significant effect of affective rumination predicting job seeking hours), results did not support Hypotheses 7 through 10 in full. Nevertheless, we still tested all possible indirect and conditional indirect effects; these are presented in Table 3. As an interpretative note, the conditional indirect effects via positive affect were not calculated given the non-significant interaction term between feedback quality at Level 1 and feedback self-efficacy at Level 2.

Based on these results (see Table 3), we found that positive affect mediated the relation between feedback quality and metacognitive strategies (estimate $=.11,95 \% \mathrm{CI}=.039, .213$ ) and the relation between feedback quality and affective rumination (estimate $=-.09,95 \% \mathrm{CI}=-.175$, -.019). We also found a significant serial indirect effect of feedback quality on the number of résumés sent via positive affect and metacognitive strategies (estimate $=.06,95 \% \mathrm{CI}=.015$, .132), as well as a significant serial indirect effect of feedback quality on hours spent job seeking via positive affect and metacognitive strategies (estimate $=.13,95 \% \mathrm{CI}=.045, .253$ ). Finally, our results indicated that the indirect effect of feedback quality on affective rumination via negative affect was significant for job seekers with lower feedback self-efficacy (estimate $=-.18$, $95 \% \mathrm{CI}=-.337,-.077)$, but not those with higher feedback self-efficacy (estimate $=-.04,95 \% \mathrm{CI}$ $=-.138, .047$ ) given that the latter $95 \% \mathrm{CI}$ included zero. In sum, our results highlight the criticality of feedback quality during job search—job seekers who receive feedback of high quality experience higher levels of positive affect, increasing engagement in metacognitive strategies, sending out more résumés and spending more time job seeking in the following week.

\section{Supplementary Analyses}

In order to provide further support for our results, we conducted two sets of supplemental 
analyses. First, we reran our model using feedback quality assessments of the first randomly chosen company participants rated. Thus, we explored whether a specific feedback event, rather a combination of multiple feedback experiences, similarly impacts job seekers' self-regulation processes. Examining feedback quality in this manner did not alter the findings of our study. In line with our prior analyses, feedback quality was positively associated with positive affect $(\gamma=$ $.44, p<.01)$ and negatively associated with negative affect $(\gamma=-.16, p<.05)$. There was a significant moderating effect of feedback self-efficacy on the relationship between feedback quality and negative, but not positive, affect $(\gamma=.29, p<.05$, and $\gamma=-.21, n s$, respectively), with the interaction having similar simple slopes results (simple slope for low feedback self-efficacy: $\gamma=-.30, t=-3.20, p<.01$; simple slope for high feedback self-efficacy: $\gamma=-.03, t=-.33, n s)$. When examining the impact on cognitive processes, positive affect increased engagement in metacognitive strategies the following week $(\gamma=.23, p<.01)$; as in our previous analyses, negative affect did not impact metacognitive strategies $(\gamma=-.03, n s)$. Further, positive affect reduced the extent to which job seekers affectively ruminated the following week $(\gamma=-.17, p<$ $.05)$, whereas negative affect increased rumination $(\gamma=.46, p<.01)$. Finally, consistent with our prior results, metacognitive strategies, but not affective rumination, significantly increased both the number of résumés sent $(\gamma=.49, p<.05$, and $\gamma=.14, n s$, respectively) and the number of hours spent job seeking $(\gamma=1.13, p<.01$, and $\gamma=.08, n s$, respectively). The indirect and conditional indirect effects also were similar: the indirect effect of feedback quality on résumés sent and hours spent job seeking via positive affect and metacognitive strategies was significant (estimate $=.05,95 \% \mathrm{CI}=.013, .120$, and estimate $=.11,95 \% \mathrm{CI}=.042, .225$, respectively $)$ Further, the indirect effect of feedback quality on affective rumination via negative affect was significant for job seekers with lower levels of feedback self-efficacy (estimate $=-.14,95 \% \mathrm{CI}=$ 
Feedback and Job Search Processes 32

$-.264,-.054)$, but not those with higher levels (estimate $=-.01,95 \% \mathrm{CI}=-.090, .061)$

Second, given that individuals' reactions to feedback may be impacted by the favorability of the feedback itself (e.g., Brett \& Atwater, 2001; Ilgen et al., 1979), we sought to explore the impact of feedback quality above and beyond feedback favorability ratings. To examine this, we conducted a supplemental study with undergraduate business school students at a large university in the Southwestern U.S., with $78.9 \%$ of our sample searching for a full-time internship/job during this study. In exchange for course credit, participants completed a 10-minute online survey, wherein they rated the favorability of feedback events during job search. Participants were asked to envision themselves as senior undergraduate students who have applied to several full-time job positions, imagining how they would react after receiving each type of feedback event. Participants were presented with the same feedback events (e.g., feedback on application; an interview offer; a job offer; a rejection letter) that job seekers in our focal study reported having received through the checklist provided at the start of each weekly survey, and were asked to rate each event on an 11-point scale $(-5=$ very unfavorably; $5=$ very favorably $)$. A total of 114 undergraduate students completed this study. The sample was largely male (58.8\%) and white $(67.5 \%)$; participants were 20.62 years of age on average $(S D=1.54$; range $=19-30)$ with an average GPA of 3.52 out of $4.00(S D=.29$; range $=2.70-4.00)$.

Based on the ratings provided, we calculated the average favorability of each feedback event (e.g., on average, receiving a rejection letter was rated as -2.56 on the favorability scale, whereas receiving a job offer was rated as 4.41). Using these averages, each weekly feedback experience in our focal study was assigned a favorability score. For instance, if a job seeker in our focal study reported that he/she had received a job offer on a particular week, a rating of 4.41 was assigned. If multiple feedback events took place within one week, we summed the 
favorability scores across the different events. Thus, a week characterized by both a job offer and a job rejection was rated as $1.85(4.41-2.56)$ on the favorability variable. As with the other focal variables of our model, we group-mean centered this control variable at Level 1. Further, when rerunning our analyses, we modeled feedback favorability on all the paths on which feedback quality were modeled; we also allowed feedback quality and feedback favorability to covary.

Results indicated that feedback favorability did not alter the findings of our study. Specifically, feedback quality increased positive affect $(\gamma=.47, p<.01)$ and lowered negative affect $(\gamma=-.23, p<.01)$ even after accounting for the effect of feedback favorability on positive $(\gamma=.03, p<.05)$ and negative affect $(\gamma=.00, n s)$. Feedback self-efficacy still moderated the relationship between feedback quality and negative affect $(\gamma=.32, p<.05)$ : the relationship was significant for job seekers with lower feedback self-efficacy (simple slope: $\gamma=-.39, t=-3.36, p<$ .01 ), but not those with higher feedback self-efficacy (simple slope: $\gamma=-.08, t=-.83, n s$ ). Similar to the findings noted above, the moderating effect of feedback self-efficacy on the relationship between feedback quality and positive affect was not significant $(\gamma=-.21, n s)$. Consistent with our prior results, positive affect positively predicted metacognitive strategies the following week $(\gamma=.22, p<.05)$, and negatively predicted affective rumination $(\gamma=-.19, p<$ $.05)$; on the other hand, negative affect increased affective rumination $(\gamma=.45, p<.01)$, but did not impact metacognitive strategies $(\gamma=-.04, n s)$. Finally, metacognitive strategies, but not affective rumination, positively predicted the number of résumés sent $(\gamma=.48, p<.05$, and $\gamma=$ $.10, n s$, respectively) and job seeking hours $(\gamma=1.13, p<.01$, and $\gamma=.11, n s$, respectively).

Our previously supported indirect and conditional indirect effects remained significant: the indirect effect of feedback quality on résumés sent and job seeking hours via positive affect and metacognitive strategies also remained significant (estimate $=.05,95 \% \mathrm{CI}=.011, .131$, and 
estimate $=.11,95 \% \mathrm{CI}=.035, .243$, respectively). Additionally, the indirect effect of feedback quality on affective rumination via negative affect was significant for job seekers with lower levels of feedback self-efficacy (estimate $=-.18,95 \% \mathrm{CI}=-.335,-.075)$, but not those with higher levels (estimate $=-.04,95 \% \mathrm{CI}=-.141, .048$ ). Thus, our results yield support for the unique effects of feedback quality: job seekers engage in effective self-regulation — in terms of increased metacognitive activities, number of résumés sent, and hours spent job seekingfollowing the receipt of high quality feedback, regardless of feedback favorability ratings ${ }^{5}$.

\section{Discussion}

Building on prior literature that has examined job search as a self-regulatory process (e.g., da Motta Veiga \& Gabriel, 2016; da Motta Veiga \& Turban, 2014; Kanfer et al., 2001; Sun et al., 2013; Wanberg et al., 2010), we integrated self-regulation theory with other theories relevant to feedback and job search to examine the role of feedback quality. In this weekly study, results demonstrated that high quality feedback is crucial for job search, as it prompted positive affective reactions, increasing metacognitive strategies and both the number of résumés job seekers send and the hours spent job seeking. Conversely, low quality feedback had detrimental effects, eliciting negative affect and affective rumination. This effect was exacerbated for job seekers with lower feedback self-efficacy, which is problematic given that affective rumination does not help job seekers. Furthermore, our supplemental analyses suggest that feedback quality

\footnotetext{
${ }^{5}$ As a robustness check, we also coded feedback favorability in an alternative manner. In our focal study, we used participants' responses to the feedback checklist provided at the beginning of each weekly survey to create two dummy codes. Specifically, the first dummy code was used to reflect positive feedback events (i.e., interview and/or job offer), while the second dummy code was used to reflect negative feedback events (i.e., rejection); all other feedback events (e.g., job seeking advice, feedback on job search materials, information about timeline) were coded as 0 for both of these dummy variables. If job seekers reported having received both favorable and unfavorable feedback (e.g., a job offer and a job rejection), the variable was coded as a 1 on the second dummy code given that negative information is often given more attention than positive information (e.g., Baumeister, Bratslavsky, Finkenauer, \& Vohs, 2001). The dummy variables were within-person centered, and modeled on all Level 1 paths; using these variables did not qualitatively alter the conclusions of the study.
} 
is critical for effective job search self-regulation irrespective of the valence of the feedback message. Thus, our results yield important theoretical and practical insights regarding job search.

\section{Theoretical Implications}

Although extant research has established that job seekers constantly need to manage their affect, cognitions, and behaviors (Sun et al., 2013; Wanberg et al., 2010), there has been a lack of research examining events that lead to these processes. By integrating job search and feedback theories, our study elucidates how feedback quality impacts self-regulatory processes during job search. Specifically, our results highlight that feedback quality influences job seekers' affective experiences. These findings are consistent with tenets of self-regulation, FIT (Kluger \& DeNisi, 1996), and AET (Weiss \& Cropanzano, 1996), which theorize the role of feedback in provoking affective reactions that subsequently influence cognitive and behavioral regulatory processes. Furthermore, by focusing on feedback quality, our research aligns with FIT (Kluger \& DeNisi, 1996) in underscoring the importance of the informational value of the feedback. Indeed, the finding that lower quality feedback elicits negative affect is consistent with the idea that feedback that lacks value prompts a focus on the self, rather than on task-motivation or tasklearning processes. In fact, qualitative data that we collected, which asked job seekers to reflect on the feedback they received each week and describe how they reacted and personally related to it, speaks to job seekers' positive reactions to higher quality feedback. One job seeker noted that: "[The feedback was that] the application... needs to be very concise and specific... It was good feedback and I strongly respected the opinions that I received;" another stated, "[The feedback was to] relate your interview answers with [the] job description... I appreciated their feedback and am still working on it." These quotations indicate that job seekers process and attend to high 
quality feedback, actively taking steps to improve their search (e.g., metacognitive strategies) ${ }^{6}$.

Moreover, by examining the moderating role of feedback self-efficacy, our findings shed light on the fact that reactions to feedback quality are not universal. Specifically, our results indicate that the negative repercussions of lower quality feedback are exacerbated for job seekers with lower feedback self-efficacy. Thus, our results align with Bandura's (1991) theorizing regarding the crucial role of self-efficacy during self-regulation. Our results are also consistent with research highlighting that individuals with lowered self-efficacy are more reactive to negative environmental cues, such as low feedback quality (i.e., behavioral plasticity theory; Brockner, 1988; Pierce et al., 1993), and less likely to engage in effective coping mechanisms (Jerusalem \& Schwarzer, 1992). Importantly, in considering feedback quality with feedback selfefficacy, the present study addresses calls to examine person-by-situation interactions that occur in the context of feedback delivery (Gabriel, Frantz, Levy, \& Hilliard, 2014; Linderbaum \& Levy, 2010). Furthermore, our study is among the first - to our knowledge - to examine how feedback-specific individual differences moderate intra-individual experiences tied to feedback episodes. Extant research examining the interactive effects has typically been conducted at the between-person level of analysis (e.g., Gabriel et al., 2014; Wang et al., 2015), ignoring the possibility that within-person relationships between feedback episodes, affective reactions, and cognitive processes vary based on between-person differences. As such, our work provides a starting point to understand how individual differences shape dynamic feedback experiences.

Beyond our consideration of feedback quality and feedback self-efficacy, our study adds to the growing literature on the role of affect during job search. Consistent with social cognitive

\footnotetext{
${ }^{6}$ As noted in our Measures section, this question pertained to the same companies for which participants rated feedback quality, and was presented before participants rated the perceptions of the quality of the feedback. Qualitative data is available upon request from the first author.
} 
theory, our results illustrate that positive affect motivates and energizes goal-directed efforts (Bandura, 1986, 1991) as job seekers' experiences of positive affect were positively related to metacognitive strategies the following week. Negative affect, on the other hand, prevented job seekers from engaging in adaptive cognitive and behavioral processes. Instead, job seekers ruminated on the causes of their negative affective experiences (Nolen-Hoeksema, 1991). To this end, the present study challenges tenets of control theory, and in particular, affect-as-information theory, which suggests that negative affect increases goal-directed efforts, while positive affect decreases them (Carver \& Scheier, 1990). As suggested by Bandura (1991), it may be the case that in situations where success is not easily attained with increased effort and, instead, requires greater attentional and cognitive demands, negative affect interferes with individuals' ability to persist. Therefore, although prior job search scholars have often invoked control theory when considering the role of affect (e.g., da Motta Veiga \& Turban, 2014), the present results suggest that social cognitive theory may offer another perspective that captures the manner in which affective experiences influence subsequent self-regulatory processes during the job search.

Finally, our study distinguishes between effective and ineffective self-regulatory cognitive processes. While extant research has typically focused on effective processes such as metacognitive strategies (e.g., da Motta Veiga \& Gabriel, 2016; Turban et al., 2009), motivation control (e.g., Turban et al., 2013; Wanberg et al., 2012), and self-efficacy (e.g., Liu et al., 2014; Sun et al., 2013), the present study adds to the job search literature by introducing affective rumination as an ineffective job search process. Importantly, affective rumination differs from other ineffective self-regulatory states, such as self-defeating cognitions (Wanberg et al., 2012), due to its unique focus on the presence of intrusive, recurrent thoughts about distress from job search (Cropley \& Zijlstra, 2011). Consistent with prior research on the detrimental effects of 
affective rumination (Nolen-Hoeksema et al., 2008), our results suggest that affective rumination may cause job seekers to attend to the negative affective aspects of their search, preventing them from engaging in tactics that can help with effective job seeking (i.e., sending more résumés and spending more time job seeking). Although we note that affective rumination did not negatively impact these behavioral criteria, we encourage scholars to continue examining whether affective rumination impedes other job search processes. Job search scholars could also contrast affective rumination with adaptive forms of rumination, such as problem-solving pondering (Querstret \& Cropley, 2012). Future research could also shed light on whether between-person differences, such as mindfulness (Long \& Christian, 2015) or resilience (Gabriel, Diefendorff, \& Erickson, 2011), help minimize the demotivating effects of affective rumination.

\section{Practical Implications}

Our results have practical implications for job seekers, career counselors, and recruiters. Consistent with feedback research (Steelman \& Rutkowski, 2004; Wang et al., 2015), recipients react more positively to specific, detailed feedback. Because receiving high quality feedback can trigger positive affective, cognitive, and behavioral self-regulatory processes, we encourage companies to deliver feedback that carries informational value. In fact, our results suggest that even rejection emails should be framed constructively (e.g., Gilliland, Groth, Baker, Dew, Polly, \& Langdon, 2001). The qualitative data further speaks to this notion. Specifically, one job seeker noted: "I wish that more feedback was given, for example: what made me not get the job/what could I have done better/what made them select the candidate that they did;" another ${ }^{7}$ mentioned how receiving quality feedback could improve his/her applications, stating: "I personally feel

\footnotetext{
${ }^{7}$ This quotation comes from a job seeker who expected to receive feedback but did not. As such, he/she was not included in our final sample. Nevertheless, the job seeker expressed his/her thoughts through an open-ended question in the survey, noting how the lack of feedback made him/her feel.
} 
disappointed for not receiving any feedback from recruiters, because I really want to know what they think of me even if I have been rejected... I also do want to know: how can I be qualified for my next application?" Thus, job seekers value quality feedback, highlighting the need for recruiters to communicate how job seekers can improve. Although we acknowledge that large corporations receive thousands_even millions (e.g., Google; Phelps, 2014)—of applications each year making it practically impossible to deliver tailored, individual feedback, recruiters should be encouraged to use other techniques to mitigate the detrimental effects of low quality feedback. Gilliland et al. (2001) found that job seekers react more favorably when rejection letters include information regarding the reasons behind the selection of the individual hired (e.g., qualifications), ultimately increasing recommendation intentions. Although this does not provide specific feedback, such information can help rejected job seekers better understand the decision and how they may improve, impacting applicant reactions and, consequently, recommendation intentions/behaviors and reapplication intentions/behaviors (cf. Gilliland, 1993; Gilliland et al., 2001; Hausknecht, Day, \& Thomas, 2004; Ryan \& Ployhart, 2000).

For job seekers, our results suggest that following up with companies to obtain high quality feedback will be valuable to their search efforts because the information provided can not only help them tailor future applications, but also spur effort toward job search behaviors (e.g., spending more time job seeking and sending more résumés) through increased positive affect and metacognitive strategies. To this end, while prior research (e.g., da Motta Veiga \& Gabriel, 2016; da Motta Veiga \& Turban, 2014; Turban et al., 2009; Wanberg et al., 2012) has suggested the development of training programs aimed toward encouraging job seekers to engage in selfregulation tactics that "pump up" (Wanberg et al., 2012, p. 280) attentional effort, we position seeking high quality feedback from companies as another mechanism by which job seekers can 
Feedback and Job Search Processes 40

be motivated and energized about their search. However, given that job seekers may receive low quality feedback despite taking such steps, our findings highlight the necessity for job seekers to confidently interpret and respond to the available feedback. Given that feedback self-efficacy is semi-malleable (Dahling et al., 2012), developing job seekers' competence regarding their ability to utilize feedback is critical in buffering them from the distress that arises from low quality feedback experiences. Thus, career counselors should advocate reaching out to companies for feedback while also developing job seekers’ feedback self-efficacy as an important buffer.

Finally, our results highlighted the "dark" side of negative affective experiences during job search. In contrast to affect-as-information theory (Carver \& Scheier, 1990), and prior research (e.g., da Motta Veiga \& Turban, 2014; Song et al., 2009), job seekers' experiences of negative affect prompted increased affective rumination, but not metacognitive strategizing. Thus, this study emphasizes the need for job seekers to harness their negative affect in a positive manner, appraising the situation as a challenge, and directing their efforts toward more effective self-regulatory processes. Importantly, career counselors can also assist in this process, helping job seekers reframe the situation in a more positive light (e.g., using cognitive reappraisal).

\section{Limitations and Future Directions}

As with any study, there are limitations. First, all variables were self-report, suggesting that our findings were influenced by single-source data. However, this was done because the job seekers were the best suited to provide evaluations of their perceptions and experiences. Further, the design of our study helps alleviate some concerns, as we utilized a within-person design that allowed us to temporally separate our variables and conduct lagged analyses, a common remedy for common method bias (Podsakoff et al., 2003). Although the possibility of reverse causality in terms of job seekers' affective states impacting perceptions of feedback quality still remains, our 
model and hypotheses are grounded in FIT (Kluger \& DeNisi, 1996) and AET (Weiss \& Cropanzano, 1996), which both state that the receipt of feedback elicits affective reactions. As Kluger and DeNisi (1996) note in their conceptualization of FIT, feedback interventions “strongly influence both pleasantness (e.g., Isen, 1987) and arousal (Kluger et al., 1996)... the two dominant dimensions underlying the affective experience" (pg. 261). Further, our weekly surveys were designed such that feedback experiences during the job search were assessed first, followed by affect. Thus, it is less likely that job seekers' affect would have colored their feedback evaluations. Further, common method biases cannot account for findings regarding our cross-level interactions given that common method biases attenuate interaction effects (Siemsen, Roth, \& Oliveria, 2010), and we within-person centered our Level 1 data to eliminate betweenperson variance (Enders \& Tofighi, 2007). Finally, the constructs assessed are likely best judged by job seekers themselves, as obtaining valid measurements from third-party raters requires others to accurately infer job seekers' affective and cognitive processes from their behaviors, which would prove to be challenging. Nonetheless, obtaining ratings from other sources could provide a more nuanced understanding. For instance, job seekers could report the actual feedback they received, which could then be objectively coded. However, this approach may be limited as objectively coded data could still be perceived as low quality to the focal job seeker.

Second, we operationalized feedback quality based on the original conceptualization by Steelman et al. (2004; see also Dahling et al., 2017; Whitaker \& Levy, 2012), reflecting the extent to which the feedback message is perceived to be useful and of informational value for job search goal-directed effort. Although this is consistent with prior work on feedback quality (e.g., Allen et al., 2010; Rosen et al., 2006; Sparr \& Sonnentag, 2008; Steelman \& Rutkowski, 2004; Wang et al., 2015; Whitaker \& Levy, 2012), we recognize that we did not capture specific 
aspects of the feedback message upon which usefulness and value can be based-for example, the relevance, specificity, and detail of the feedback (Steelman et al., 2004; Wang et al., 2015). As such, we recommend that organizational scholars better examine the intra-individual factors that help determine perceptions of feedback quality week-to-week (or even day-to-day).

Third, although we followed prior work that has focused on new labor market entrants (e.g., da Motta Veiga \& Gabriel, 2016; Song et al., 2009; Sun et al., 2013), our sample was comprised of undergraduate students. While the informational value tied to high quality feedback may be particularly beneficial for job seekers with less experience with the labor market, we expect quality feedback to be similarly valuable for other types of seekers as it provides guidance regarding the (in)effectiveness of search strategies, thereby alleviating part of the uncertainty and apprehension inherent in the search process (da Motta Veiga et al., 2018). Nevertheless, we encourage future research to consider the role of feedback quality for other types of job seekers (e.g., job losers, employed seekers; Boswell, Zimmerman, \& Swider, 2012) to determine whether our results generalize. Further, while our study focused on the self-regulatory processes that unfold after job seekers receive high versus low quality feedback weekly, future research can also explore factors that drive perceptions of feedback quality. For example, certain types of job seekers — such as those with more extensive job seeking experience compared to new labor market entrants - may perceive feedback quality differently due to a broader schema of what high quality feedback is, and how this feedback impacts their job search. That said, an examination of the qualitative data provided by new labor market entrants in our study pertaining to ratings of high (e.g., "Relate your interview answers with job description") and low quality feedback (e.g., "She didn't really give me much feedback on how the interview actually went, just that I should be hearing back in the next week or so") gives us reason to believe that such 
feedback messages would be similarly rated by more experienced job seekers. We encourage scholarship to more thoroughly unpack this issue, in addition to replicating our work in different types of job seeking contexts (e.g., those who are chronically unemployed vs. employed).

Relatedly, while we examined feedback self-efficacy as a stable, between-person trait, it is possible that there is within-person variability in feedback self-efficacy, particularly among first-time job seekers (i.e., new labor market entrants). Indeed, recent theorizing suggests that feedback self-efficacy may be semi-malleable (Dahling et al., 2012). To offer a preliminary investigation of this idea, we conducted a supplemental study with new labor market entrants at a large Southwestern U.S. university following a similar protocol as our focal study (Level $1 n=$ 330; Level $2 n=88$ ), and utilizing a within-person measure of feedback self-efficacy adapted from Linderbaum and Levy's (2010) measure. Null model results in Mplus indicated that 69.5\% of the variance in feedback self-efficacy was attributable to within-person variance. Thus, we encourage future research to explore the dynamics surrounding feedback self-efficacy in terms of the factors that influence such within-person variability; it is possible that certain aspects of the feedback message — for instance, the delivery of the feedback or the valence of the messageimpact the extent to which individuals feel confident in their abilities to effectively interpret and respond to feedback events. Additionally, it may also behoove researchers to examine whether feedback self-efficacy exhibits greater within-person variability among job seekers who are new to job seeking compared to those who are experienced (e.g., employed job seekers), further highlighting the importance of providing new labor market entrants with higher quality feedback to prevent ineffective self-regulation.

We also encourage a more in-depth investigation into the types and frequency of feedback events that occur. In the present case, job seekers experienced a total of 815 feedback 
events across the seven weeks of our study: 496 (60.9\%) were neutral events, such as feedback on one's application; 264 (32.4\%) reflected positive feedback events, which included interviews and/or job offers; and the remaining $55(6.8 \%)$ were negative feedback events (i.e., rejections) ${ }^{8}$. Because this breakdown simply reflects whether an event was positive, neutral, or negative (i.e., not the number of offers or rejections received), it likely represents a rather conservative estimate of feedback events, and rejections in particular. That said, any rejection is still likely to be a very negative experience for job seekers (e.g., Baumeister et al., 2001), impacting their subsequent self-regulatory efforts. Future research may benefit from adopting a more fine-grained approach to job seekers' intra-individual experiences, using event-contingent methods (Beal \& Gabriel, 2019) to capture more precise estimates of job search events. Whereas the present examination focuses on the types of events experienced, researchers may also consider the interpersonal dynamics and relational cues that typically underlie feedback events.

Finally, we were unable to assess objective outcomes, such as the number of interview or job offers received, because we conceptualized these as examples of feedback. As such, we were concerned about endogeneity; including objective outcomes would have resulted in a circular model, in which job offers (a feedback event) were predicting job offers. To provide greater support for our decisions surrounding the examination of job search intensity (i.e., number of résumés sent) and job search effort (i.e., hours spent job seeking), we explored whether these behaviors correlated with outcomes of success at the between-person level of analysis ${ }^{9}$. The number of résumés sent and the number of hours spent job seeking positively correlated with the number of interview offers received ( $r=.48$ and $.53, p<.01$, respectively), but not with the

\footnotetext{
${ }^{8}$ We thank the editorial team members for encouraging us to provide greater context surrounding job seekers' typical feedback experiences, and hope that this serves as a launching point for future intra-individual research. ${ }^{9}$ We thank the editorial team members for providing valuable feedback regarding this idea.
} 
number of offers received ( $r=.06, n s$ and $r=.17, n s$, respectively). In contrast, the total number of interview offers received across the seven weeks of the study positively correlated with the total number of offers received $(r=.36, p<.01)$. These results are consistent with the unfolding process of job search (da Motta Veiga et al., 2018), which suggests that exerting greater effort (e.g., spending more time job searching) and searching with increased intensity (e.g., sending more résumés) leads to proximal outcomes, such as job interviews. In turn, job interviews lead to distal success outcomes, such as job offers. Thus, the pattern of findings noted here suggests that greater effort and intensity correlate with job search success, providing greater support regarding our measurement decisions. Nevertheless, we encourage future research to consider other objective criteria, such as starting salary (e.g., Brasher \& Chen, 1999), pre- or post-entry personorganization perceptions, employment quality, and job attitudes (e.g., Saks \& Ashforth, 2002).

\section{Conclusion}

To our knowledge, the present study is among the first to examine the role of feedback during job search. Results indicate that receiving higher quality feedback during job search engenders effective self-regulation, whereas receiving low quality feedback is detrimental, preventing engagement in job search behaviors. Furthermore, results illustrated the moderating role of feedback self-efficacy, noting that the harmful effects of lower quality feedback are exacerbated for job seekers with low feedback self-efficacy. In sum, our findings suggest that receiving feedback that has quality informational value is crucial to successful self-regulation. 
Feedback and Job Search Processes 46

\section{References}

Allen, T. D., Shockley, K. M., \& Poteat, L. (2010). Protégé anxiety attachment and feedback in mentoring relationships. Journal of Vocational Behavior, 77, 73-80. doi: 10.1016/j.jvb.2010.02.007

Anseel, F., Beatty, A. S., Shen, W., Lievens, F., \& Sackett, P. R. (2015). How are we doing after 30 years? A meta-analytic review of the antecedents and outcomes of feedback-seeking behavior. Journal of Management, 41, 318-348. doi: 10.1177/0149206313484521

Ashford, S. J. (1986). Feedback-seeking in individual adaptation: A resource perspective. Academy of Management Journal, 29, 465-487. doi: 10.2307/256219

Ashford, S. J., \& Tsui, A. S. (1991). Self-regulation for managerial effectiveness: The role of active feedback seeking. Academy of Management Journal, 34, 251-280. doi: $10.2307 / 256442$

Bandura, A. (1986). Social foundations of thought and action: A social cognitive theory. Englewood Cliffs, NJ: Prentice Hall.

Bandura, A. (1989). Human agency in social cognitive theory. American Psychologist, 44, 11751184. doi: 10.1037/0003-066X.44.9.1175

Bandura, A. (1991). Social cognitive theory of self-regulation. Organizational Behavior and Human Decision Processes, 50, 248-287. doi: 10.1016/0749-5978(91)90022-L

Bandura, A., \& Locke, E. A. (2003). Negative self-efficacy and goal effects revisited. Journal of Applied Psychology, 88, 87-99. doi: 10.1037/0021-9010.88.1.87

Baumeister, R. F., Bratslavsky, E., Finkenauer, C., \& Vohs, K. D. (2001). Bad is stronger than good. Review of General Psychology, 5, 323-370. doi: 10.1037/1089-2680.5.4.323

Beal, D. J. (2015). ESM 2.0: State of the art and future potential of experience sampling methods in organizational research. Annual Review of Organizational Psychology and Organizational Behavior, 2, 383-407. doi: 10.1146/annurev-orgpsych-032414-111335

Beal, D. J., \& Gabriel, A. S. (2019). Looking within: An examination, combination, and extension of within-person methods across multiple levels of analysis. In S. E. Humphrey \& J. M. LeBreton (Eds.), The handbook for multilevel theory, measurement, and analysis (pp. 305-327). Washington, DC: American Psychological Association.

Beal, D. J., \& Weiss, H. M. (2003). Methods of ecological momentary assessment in organizational research. Organizational Research Methods, 6, 440-464. doi: $10.1177 / 1094428103257361$ 
Boswell, W. R., Zimmerman, R. D., \& Swider, B. W. (2012). Employee job search: Toward an understanding of search context and search objectives. Journal of Management, 38, 129163. doi: $10.1177 / 0149206311421829$

Brasher, E. E., \& Chen, P. Y. (1999). Evaluation of success criteria in job search: A process perspective. Journal of Occupational and Organizational Psychology, 72, 57-70. doi: $10.1348 / 096317999166491$

Brockner, J. (1983). Low self-esteem and behavioral plasticity: Some implications. In L. Wheeler \& P. R. Shaver (Eds.), Review of personality and social psychology (vol. 4, pp. 237-271). Beverly Hills, CA: Sage Publications.

Brockner, J. (1988). Self-esteem at work: Research, theory, and practice. Lexington, MA: Lexington Books.

Brett, J. F., \& Atwater, L. E. (2001). 360 feedback: Accuracy, reactions, and perceptions of usefulness. Journal of Applied Psychology, 86, 930-942. doi: 10.1037/00219010.86.5.930

Cacioppo, J. T., Gardner, W. L., \& Berntson, G. G. (1999). The affect system has parallel and integrative processing components: Form follows function. Journal of Personality and Social Psychology, 76, 839-855. doi: 10.1037/0022-3514.76.5.839

Carver, C. S., \& Scheier, M. F. (1981). The self-attention-induced feedback loop and social facilitation. Journal of Experimental Social Psychology, 17, 545-568. doi: 10.1016/00221031(81)90039-1

Carver, C. S., \& Scheier, M. F. (1990). Origins and functions of positive and negative affect: A control-process view. Psychological Review, 97, 19-35. doi: 10.1037/0033-295X.97.1.19

Chawla, N., Gabriel, A. S., Dahling, J. J., \& Patel, K. (2016). Feedback dynamics are critical to improving performance management systems. Industrial and Organizational Psychology: Perspectives on Science and Practice, 9, 620-626.

Cropley, M., Michalianou, G., Pravettoni, G., \& Millward, L. J. (2012). The relation of postwork ruminative thinking with eating behavior. Stress and Health, 28, 23-30. doi: 10.1002/smi.1397

Cropley, M., \& Zijlstra, F. R. H. (2011). Work and rumination. In J. Langan-Fox \& C. L. Cooper (Eds.), Handbook of stress in the occupations (pp. 487-503). Camberley, UK: Edward Elgar Publishing.

da Motta Veiga, S. P., \& Gabriel, A. S. (2016). The role of self-determined motivation in job search: A dynamic approach. Journal of Applied Psychology, 101, 350-361. doi: 10.1037/ap10000070 
da Motta Veiga, S. P., \& Turban, D. B. (2014). Are affect and perceived stress detrimental or beneficial to job seekers? The role of learning goal orientation in job search selfregulation. Organizational Behavior and Human Decision Processes, 125, 193-203. doi: 10.1016/j.obhdp.2014.09.007

da Motta Veiga, S. P., Turban, D. B., Gabriel, A. S., \& Chawla, N. (2018). From the unfolding process to self-regulation in job search: Integrating between- and within-person approaches. In M. R. Buckley, J. R. B. Halbesleben, \& A. R. Wheeler (Vol. Eds.), Research in Personnel and Human Resource Management (vol. 36, pp. 243-274). Emerald Publishing.

Dahling, J. J., Chau, S. L., \& O’Malley, A. (2012). Correlates and consequences of feedback orientation in organizations. Journal of Management, 38, 531-546. doi: $10.1177 / 0149206310375467$

Dahling, J. J., Gabriel, A. S., \& MacGowan, R. (2017). Understanding typologies of feedback environment perceptions: A latent profile investigation. Journal of Vocational Behavior, 101, 133-148. doi: 10.1016/j.jvb.2017.05.007

Denson, T. F., Fabiansson, E. C., Creswell, J. D., \& Pedersen, W. C. (2009). Experimental effects of rumination styles on salivary cortisol responses. Motivation and Emotion, 33, 42-48. doi: 10.1007/s11031-008-9114-0

Ebner-Priemer, U. W., \& Trull, T. J. (2011). Investigating temporal instability in psychological variables: Understanding the real world as time dependent. In M. R. Mehl \& T. S. Conner (Eds.), Handbook of research methods for studying daily life (pp. 423-458). New York, NY: Guilford Press.

Elicker, J. D., Levy, P. E., \& Hall, R. J. (2006). The role of leader-member exchange in the performance appraisal process. Journal of Management, 32, 531-551. doi: $10.1177 / 0149206306286622$

Enders, C. K., \& Tofighi, D. (2007). Centering predictor variables in cross-sectional multilevel models: A new look at an old issue. Psychological Methods, 12, 121-138. doi: 10.1037/1082-989X.12.2.121

Endler, N. S., \& Magnusson, D. (1976). Toward an interactional psychology of personality. Psychological Bulletin, 83, 956-974. doi: 10.1037/0033-2909.83.5.956

Folkman, S., \& Moskowitz, J. T. (2000). Positive affect and the other side of coping. American Psychologist, 55, 647-654. doi: 10.1037/0003-066X.55.6.647

Foo, M. D., Uy, M. A., \& Baron, R. A. (2009). How do feelings influence effort? An empirical study of entrepreneurs' affect and venture effort. Journal of Applied Psychology, 94, 1086-1094. doi: 10.1037/a0015599 
Fredrickson, B. L. (1998). What good are positive emotions? Review of General Psychology, 2, 300-319. doi: 10.1037/1089-2680.2.3.300

Fredrickson, B. L. (2001). The role of positive emotions in positive psychology: The broadenand-build theory of positive emotions. American Psychologist, 56, 218-226. doi: 10.1037/0003-066X.56.3.218

Gabriel, A. S., Diefendorff, J. M., Chandler, M. M., Moran, C. M., \& Greguras, G. J. (2014). The dynamic relationships of work affect and job satisfaction with perceptions of fit. Personnel Psychology, 67, 389-420. doi: 10.1111/peps. 12042

Gabriel, A. S., Diefendorff, J. M., \& Erickson, R. J. (2011). The relations of daily task accomplishment satisfaction with changes in affect: A multilevel study in nurses. Journal of Applied Psychology, 96, 1095-1104. doi: 10.1037/a0023937

Gabriel, A. S., Frantz, N. B., Levy, P. E., \& Hilliard, A. W. (2014). The supervisor feedback environment is empowering, but not all the time: Feedback orientation as a critical moderator. Journal of Occupational and Organizational Psychology, 87, 487-506. doi: 10.1111/joop. 12060

Gabriel, A. S., Koopman, J., Rosen, C. C., \& Johnson, R. E. (2018). Helping others or helping oneself? An episodic examination of the behavioral consequences of helping at work. Personnel Psychology, 71, 85-107. doi: 10.111/peps.12229

Gabriel, A. S., Podsakoff, N. P., Beal, D. J., Scott, B. A., Sonnentag, S., Trougakos, J. P., \& Butts, M. M. (in press). Experience sampling methodology: A discussion of critical trends and considerations for scholarly advancement. Organizational Research Methods.

Gilliland, S. W. (1993). The perceived fairness of selection systems: An organizational justice perspective. Academy of Management Review, 18, 694-734. doi: 10.5465/amr.1993.9402210155

Gilliland, S. W., Groth, M., Baker, R. C., Dew, A. E., Polly, L. M., \& Langdon, J. C. (2001). Improving applicants' reactions to rejection letters: An application of fairness theory. Personnel Psychology, 54, 669-703. doi: 10.1111/j.1744-6570.2001.tb00227.x

Gist, M. E. (1987). Self-efficacy: Implications for organizational behavior and human resource management. Academy of Management Review, 12, 472-485. doi: 10.5465/AMR.1987.4306562

Hausknecht, J. P., Day, D. V., \& Thomas, S. C. (2004). Applicant reactions to selection procedures: An updated model and meta-analysis. Personnel Psychology, 57, 639-683. doi: 10.1111/j.1744-6570.2004.00003.x 
Hofmann, D. A., Griffin, M. A., \& Gavin, M. B. (2000). The application of hierarchical linear modeling to organizational research. In K. J. Klein \& S. W. J. Kozlowski (Eds.), Multilevel theory, research, and methods in organizations: Foundations, extensions, and new directions (pp. 467-511). San Francisco, CA: Jossey-Bass.

Ilgen, D. R., Fisher, C. D., \& Taylor, M. S. (1979). Consequences of individual feedback on behavior in organizations. Journal of Applied Psychology, 64, 349-371. doi: 10.1037/0021-9010.64.4.349

Ilies, R., De Pater, I. E., \& Judge, T. (2007). Differential affective reactions to negative and positive feedback, and the role of self-esteem. Journal of Managerial Psychology, 22, 590-609. doi: 10.1108/02683940710778459

Ilies, R., \& Judge, T. A. (2005). Goal regulation across time: The effects of feedback and affect. Journal of Applied Psychology, 90, 453-467. doi: 10.1037/0021-9010.90.3.453

Isen, A. M. (1987). Positive affect, cognitive processes, and social behavior. Advances in Experimental Social Psychology, 20, 203-253. doi: 10.1016/S0065-2601(08)60415-3

Isen, A. M. (1993). Positive affect and decision-making. In M. Lewis \& J. Haviland (Eds.), Handbook of emotion (pp. 261-277). New York, NY: Guilford Press.

Isen, A. M., \& Reeve, J. (2005). The influence of positive affect on intrinsic and extrinsic motivation: Facilitating enjoyment of play, responsible work behavior, and selfcontrol. Motivation and Emotion, 29, 295-323. doi: 10.1007/s11031-006-9019-8

Jerusalem, M., \& Schwarzer, R. (1992). Self-efficacy as a resource factor in stress appraisal processes. In R. Schwarzer (Ed.), Self-efficacy: Thought control of action (pp. 195-213). NY, New York: Taylor \& Francis Group.

Jex, S. M., \& Bliese, P. D. (1999). Efficacy beliefs as a moderator of the impact of work-related stressors: A multilevel study. Journal of Applied Psychology, 84, 349-361. doi: 10.1037/0021-9010.84.3.349

Kanfer, R., \& Ackerman, P. L. (1989). Motivation and cognitive abilities: An integrative/aptitude-treatment interaction approach to skill acquisition. Journal of Applied Psychology, 74, 657-690. doi: 10.1037/0021-9010.74.4.657

Kanfer, R., Wanberg, C. R., \& Kantrowitz, T. M. (2001). Job search and employment: A personality-motivational analysis and meta-analytic re-view. Journal of Applied Psychology, 86, 837-855. doi: 10.1037/0021-9010.86.5.837

Kline, T. J. B. (2005). Psychological testing: A practical approach to design and evaluation. Thousand Oaks, CA: Sage Publications, Inc. 
Kluger, A. N., \& DeNisi, A. (1996). The effects of feedback interventions on performance: A historical review, a meta-analysis, and a preliminary feedback intervention theory. Psychological Bulletin, 119, 254-284. doi: 10.1037/0033-2909.119.2.254

Koen, J., van Vianen, A. E., van Hooft, E. A., \& Klehe, U. C. (2016). How experienced autonomy can improve job seekers' motivation, job search, and chance of finding reemployment. Journal of Vocational Behavior, 95, 31-44. doi: 10.1016/j.jvb.2016.07.003

Koopman, J., Howe, M., \& Hollenbeck, J. R. (2014). Pulling the Sobel test up by its bootstraps. In C. E. Lance \& R. J. Vandenberg (Eds.), More statistical and methodological myths and urban legends. New York, NY: Routledge.

Koopman, J., Lanaj, K., \& Scott, B. A. (2016). Integrating the bright and dark sides of OCB: A daily investigation of the benefits and costs of helping others. Academy of Management Journal, 59, 414-435. doi: 10.5465/amj.2014.0262

Lam, S. S., Yik, M. S., \& Schaubroeck, J. (2002). Responses to formal performance appraisal feedback: The role of negative affectivity. Journal of Applied Psychology, 87, 192-201. doi: 10.1037//0021-9010.87.1.192

Lanaj, K., Johnson, R. E., \& Lee, S. M. (2016). Benefits of transformational behaviors for leaders: A daily investigation of leader behaviors and need fulfillment. Journal of Applied Psychology, 101, 237-251. doi: 10.1037/ap110000052

Lanaj, J., Johnson, R. E., \& Wang, M. (2016). When lending a hand depletes the will: The daily costs and benefits of helping. Journal of Applied Psychology, 101, 1097-1110. doi: 10.1037/ap10000118

Lazarus, R. S. (1991). Progress on a cognitive-motivational-relational theory of emotion. American Psychologist, 46, 819-834. doi: 10.1037/0003-066X.46.8.819

Linderbaum, B. A., \& Levy, P. E. (2010). The development and validation of the Feedback Orientation Scale (FOS). Journal of Management, 36, 1372-1405. doi: $10.1177 / 0149206310373145$

Liu, S., Wang, M., Liao, H., \& Shi, J. (2014). Self-regulation during job search: The opposing effects of employment self-efficacy and job search behavior self-efficacy. Journal of Applied Psychology, 99, 1159-1172. doi: 10.1037/a0036692

London, M., \& Smither, J. W. (2002). Feedback orientation, feedback culture, and the longitudinal performance management process. Human Resource Management Review, 12, 81-100. doi: 10.1016/S1053-4822(01)00043-2 
Feedback and Job Search Processes 52

Long, E. C., \& Christian, M. S. (2015). Mindfulness buffers retaliatory responses to injustice: A regulatory approach. Journal of Applied Psychology, 100, 1409-1422. doi: 10.1037/ap10000019

Lopez-Kidwell, V., Grosser, T. J., Dineen, B. R., \& Borgatti, S. P. (2013). What matters when: A multistage model and empirical examination of job search effort. Academy of Management Journal, 56, 1655-1678. doi: 10.5465/amj.2011.0546

Lord, R. G., Diefendorff, J. M., Schmidt, A. M., \& Hall, R. J. (2010). Self-regulation at work. Annual Review of Psychology, 61, 543-568. doi: 10.1146/annurev.psych.093008.100314

Luszczynska, A., Scholz, U., \& Schwarzer, R. (2005). The general self-efficacy scale: Multicultural validation studies. The Journal of Psychology, 139, 439-457. doi: 10.3200/JRLP.139.5.439-457

Martin, L. L., \& Tesser, A. (1996). Some ruminative thoughts. In R. S. Wyer (Ed.), Ruminative thoughts (pp. 1-49). Mahwah, NJ: Lawrence Erlbaum Associates, Inc.

Meier, L. L., Gross, S., Spector, P. E., \& Semmer, N. K. (2013). Relationship and task conflict at work: Interactive short-term effects on angry mood and somatic complaints. Journal of Occupational Health Psychology, 18, 144-156. doi: 10.1037/a0032090

Moberly, N. J., \& Watkins, E. R. (2010). Negative affect and ruminative self-focus during everyday goal pursuit. Cognition \& Emotion, 24, 729-739. doi: $10.1080 / 02699930802696849$

Muthén, L. K., \& Muthén, B. O. (1998-2013). Mplus user's guide. 7th edition. Los Angeles, CA: Muthén \& Muthén.

Nathan, B. R., Mohrman, A. M. Jr., \& Milliman, J. (1991). Interpersonal relations as a context for the effects of appraisal interviews on performance and satisfaction: A longitudinal study. Academy of Management Journal, 34, 352-369. doi: 10.2307/256446

Nolen-Hoeksema, S. (1991). Responses to depression and their effects on the duration of depressive episodes. Journal of Abnormal Psychology, 100, 569-582. doi: 10.1037/0021843X.100.4.569

Nolen-Hoeksema, S., Wisco, B. E., \& Lyubomirsky, S. (2008). Rethinking rumination. Perspectives on Psychological Science, 3, 400-424. doi: 10.1111/j.17456924.2008.00088.x

Parker, S. K., Bindl, U. K., \& Strauss, K. (2010). Making things happen: A model of proactive motivation. Journal of Management, 36, 827-856. doi: 10.1177/0149206310363732 
Phelps, S. (2014, August 5). Cracking into google: 15 reasons why more than 2 million people apply each year. Forbes. Retrieved from https://www.forbes.com/sites/stanphelps/2014/08/05/cracking-into-google-the-15reasons-why-over-2-million-people-apply-each-year/\#30d7d0ac2038

Pierce, J. L., Gardner, D. G., Dunham, R. B., \& Cummings, L. L. (1993). Moderation by organization-based self-esteem of role condition-employee response relationships. Academy of Management Journal, 36, 271-288. doi: 10.5465/256523

Podsakoff, P. M., MacKenzie, S. B., Lee, J. Y., \& Podsakoff, N. P. (2003). Common method biases in behavioral research: A critical review of the literature and recommended remedies. Journal of Applied Psychology, 88, 879-903. doi: 10.1037/0021-9010.88.5.879

Pravettoni, G., Cropley, M., Leotta, S. N., \& Bagnara, S. (2007). The differential role of mental rumination among industrial and knowledge workers. Ergonomics, 50, 1931-1940. doi: $10.1080 / 00140130701676088$

Preacher, K. J., \& Hayes, A. F. (2004). SPSS and SAS procedures for estimating indirect effects in simple mediation models. Behavior Research Methods, 36, 717-731. doi: 10.3758/BF03206553

Preacher, K. J., \& Hayes, A. F. (2008). Asymptotic and resampling strategies for assessing and comparing indirect effects in multiple mediator models. Behavior Research Methods, 40, 879-891. doi: 10.3758/BRM.40.3.879

Querstret, D., \& Cropley, M. (2012). Exploring the relationship between work-related rumination, sleep quality, and work-related fatigue. Journal of Occupational Health Psychology, 17, 341-353. doi: 10.1037/a0028552

Robinson, M. D., \& Clore, G. L. (2002). Belief and feeling: Evidence for an accessibility model of emotional self-report. Psychological Bulletin, 128, 934-960. doi: 10.1037/00332909.128.6.934

Rosen, C. C., Levy, P. E., \& Hall, R. J. (2006). Placing perceptions of politics in the context of the feedback environment, employee attitudes, and job performance. Journal of Applied Psychology, 91, 211-220. doi: 10.1037/0021-9010.91.1.211

Rojstaczer, S. (2009). Grade inflation at American colleges and universities. Retrieved from www.gradeinflation.com

Ryan, A. M., \& Ployhart, R. E. (2000). Applicants' perceptions of selection procedures and decisions: A critical review and agenda for the future. Journal of Management, 26, 565606. doi: 10.1016/S0149-2063(00)00041-6 
Saks, A. M. (2005). Job search success: A review and integration of the predictors, behaviors, and outcomes. In S. Brown \& R. Lent (Eds.), Career development and counseling: Putting theory and research to work (pp. 155-179). Hoboken, NJ: Wiley.

Saks, A. M. (2006). Multiple predictors and criteria of job search success. Journal of Vocational Behavior, 68, 400-415. doi: 10.1016/j.jvb.2005.10.001

Saks, A. M., \& Ashforth, B. E. (2002). Is job search related to employment quality? It all depends on the fit. Journal of Applied Psychology, 87, 646-654. doi: 10.1037/00219010.87.4.646

Scott, B. A., Colquitt, J. A., Paddock, E. L., \& Judge, T. A. (2010). A daily investigation of the role of manager empathy on employee well-being. Organizational Behavior and Human Decision Processes, 113, 127-140. doi: 10.1016/j.obhdp.2010.08.001

Seo, M. G., Barrett, L. F., \& Bartunek, J. M. (2004). The role of affective experience in work motivation. Academy of Management Review, 29, 423-439. doi: 10.5465/AMR.2004.13670972

Siemsen, E., Roth, A., \& Oliveira, P. (2010). Common method bias in regression models with linear, quadratic, and interaction effects. Organizational Research Methods, 13, 456-476. doi: $10.1177 / 1094428109351241$

Snijders, T., \& Bosker, R. (1999). Multilevel analysis: An introduction to basic and advanced multilevel modeling. Thousand Oaks, CA: Sage.

Song, Z., Uy, M. A., Zhang, S., \& Shi, K. (2009). Daily job search and psychological distress: Evidence from China. Human Relations, 62, 1171-1197. doi: $10.1177 / 0018726709334883$

Sparr, J. L., \& Sonnentag, S. (2008). Feedback environment and well-being at work: The mediating role of personal control and feelings of helplessness. European Journal of Work and Organizational Psychology, 17, 388-412. doi: 10.1080/13594320802077146

Spector, P. E., \& Brannick, M. T. (2011). Methodological urban legends: The misuse of statistical control variables. Organizational Research Methods, 14, 287-305. doi: $10.1177 / 1094428110369842$

Steelman, L. A., Levy, P. E., \& Snell, A. F. (2004). The feedback environment scale: Construct definition, measurement, and validation. Educational and Psychological Measurement, 64, 165-184. doi: 10.1177/0013164403258440

Steelman, L. A., \& Rutkowski, K. A. (2004). Moderators of employee reactions to negative feedback. Journal of Managerial Psychology, 19, 6-18. doi: $10.1108 / 02683940410520637$ 
Strecher, V. J., McEvoy DeVellis, B., Becker, M. H., \& Rosenstock, I. M. (1986). The role of self-efficacy in achieving health behavior change. Health Education Quarterly, 13, 7392. doi: $10.1177 / 109019818601300108$

Sun, S., Song, Z., \& Lim, V. K. G. (2013). Dynamics of the job search process: Developing and testing a mediated moderation model. Journal of Applied Psychology, 98, 771-784. doi: $10.1037 / \mathrm{a} 0033606$

Turban, D. B., Lee, F. K., da Motta Veiga, S. P., Haggard, D. L., \& Wu, S. Y. (2013). Be happy, don't wait: The role of trait affect in job search. Personnel Psychology, 66, 483-514. doi: $10.1111 /$ peps. 12027

Turban, D. B., Stevens, C. K., \& Lee, F. K. (2009). Effects of conscientiousness and extraversion on new labor market entrants' job search: The mediating role of meta-cognitive activities and positive emotions. Personnel Psychology, 62, 553-573. doi: 10.1111/j.1744-6570 .2009.01148.x

Uy, M. A., Lin, K. J., \& Ilies, R. (2017). Is it better to give or receive? The role of help in buffering the depleting effects of surface acting. Academy of Management Journal, 60, 1442-1461. doi: 10.5465/amj.2015.0611

VandeWalle, D., Cron, W. L., \& Slocum Jr, J. W. (2001). The role of goal orientation following performance feedback. Journal of Applied Psychology, 86, 629-640. doi: 10.1037/00219010.86.4.629

Van Katwyk, P. T., Fox, S., Spector, P. E., \& Kelloway, E. K. (2000). Using the Job-Related Affective Well-Being Scale (JAWS) to investigate affective responses to work stressors. Journal of Occupational Health Psychology, 5, 219-230. doi: 10.1037/10768998.5.2.219

Wanberg, C. R. (2012). The individual experience of unemployment. Annual Review of Psychology, 63, 369-396. doi: 10.1146/annurev-psych-120710-100500

Wanberg, C. R., Glomb, T. M., Song, Z., \& Sorenson, S. (2005). Job-search persistence during unemployment: A 10-wave longitudinal study. Journal of Applied Psychology, 90, 411430. doi: $10.1037 / 0021-9010.90 .3 .411$

Wanberg, C. R., Zhu, J., \& Van Hooft, E. (2010). The job search grind: Perceived progress, selfreactions, and self-regulation of search effort. Academy of Management Journal, 53, 788-807. doi: 10.5465/AMJ.2010.52814599

Wanberg, C. R., Zhu, J., Kanfer, R., \& Zhang, Z. (2012). After the pink slip: Applying dynamic motivation frameworks to the job search experience. Academy of Management Journal, 55, 261-284. doi: 10.5465/amj.2010.0157 
Feedback and Job Search Processes 56

Wang, C. S., Sivanathan, N., Narayanan, J., Ganegoda, D. B., Bauer, M., Bodenhausen, G. V., \& Murnighan, K. (2011). Retribution and emotional regulation: The effects of time delay in angry economic interactions. Organizational Behavior and Human Decision Processes, 116, 46-54. doi: 10.1016/j.obhdp.2011.05.007

Wang, M., Burlacu, G., Truxillo, D., James, K., \& Yao, X. (2015). Age differences in feedback reactions: The roles of employee feedback orientation on social awareness and utility. Journal of Applied Psychology, 100, 1296-1308. doi: 10.1037/a0038334

Wang, M., Liu, S. Q., Liao, H., Gong, Y. P., Kammeyer-Mueller, J., \& Shi, J. Q. (2013). Can’t get it out of my mind: Employee rumination after customer mistreatment and negative mood in the next morning. Journal of Applied Psychology, 98, 989-1004. doi: $10.1037 / \mathrm{a} 0033656$

Webb, T. L., Miles, E., \& Sheeran, P. (2012). Dealing with feeling: A meta-analysis of the effectiveness of strategies derived from the process model of emotion regulation. Psychological Bulletin, 138, 775-808. doi: 10.1037/a0027600

Weiss, H. M., \& Cropanzano, R. (1996). Affective events theory: A theoretical discussion of the structure, causes, and consequences of affective experiences at work. In B. M. Staw, \& L. L. Cummings (Eds.), Research in organizational behavior (pp. 1-74). Greenwich, CT: JAI Press.

Weiss, H. M., \& Rupp, D. E. (2011). Experiencing work: An essay on a person-centric work psychology. Industrial and Organizational Psychology, 4, 83-97. doi: 10.1111/j.17549434.2010.01302.x

Whitaker, B. G., \& Levy, P. (2012). Linking feedback quality and goal orientation to feedback seeking and job performance. Human Performance, 25, 159-178. doi: $10.1080 / 08959285.2012 .658927$

Yang, J., \& Diefendorff, J. M. (2009). The relations of daily counterproductive workplace behavior with emotions, situational antecedents, and personality moderators: A diary study in Hong Kong. Personnel Psychology, 62, 259-295. doi: 10.1111/j.17446570.2009.01138.x 


\section{Table 1}

Means, Standard Deviations, and Correlations of Study Variables

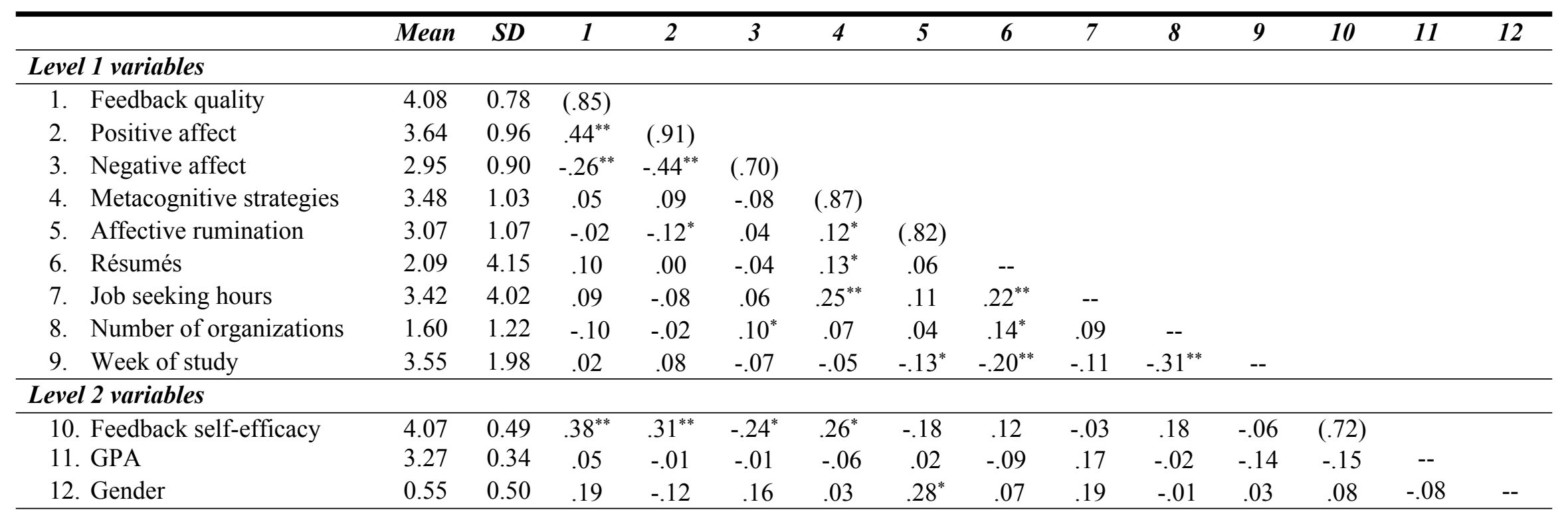

Note. Level $1 n=305-394$; Level $2 n=93 . S D=$ standard deviation. Average reliability across weeks is along the diagonal. Gender was coded such that $0=$ male, $1=$ female. Number of organizations represents the number of organizations job seekers received feedback from weekly. Correlations amongst the Level 1 variables are within-person centered correlations. Level 1 variables were aggregated to Level 2 in order to analyze correlations with feedback self-efficacy and our control variables; as a note, the control variables (e.g., GPA, gender, number of organizations, week of study) are not included in the test of our hypotheses, but are presented here for completeness. Level 1 reliabilities are the average reliability across the seven weeks of the study. The reliability of feedback quality reflects ratings from the first company as all participants reported feedback from at least one company.

${ }^{*} p<.05,{ }^{* *} p<.01$. 


\section{Table 2}

Multilevel Path Analysis Results

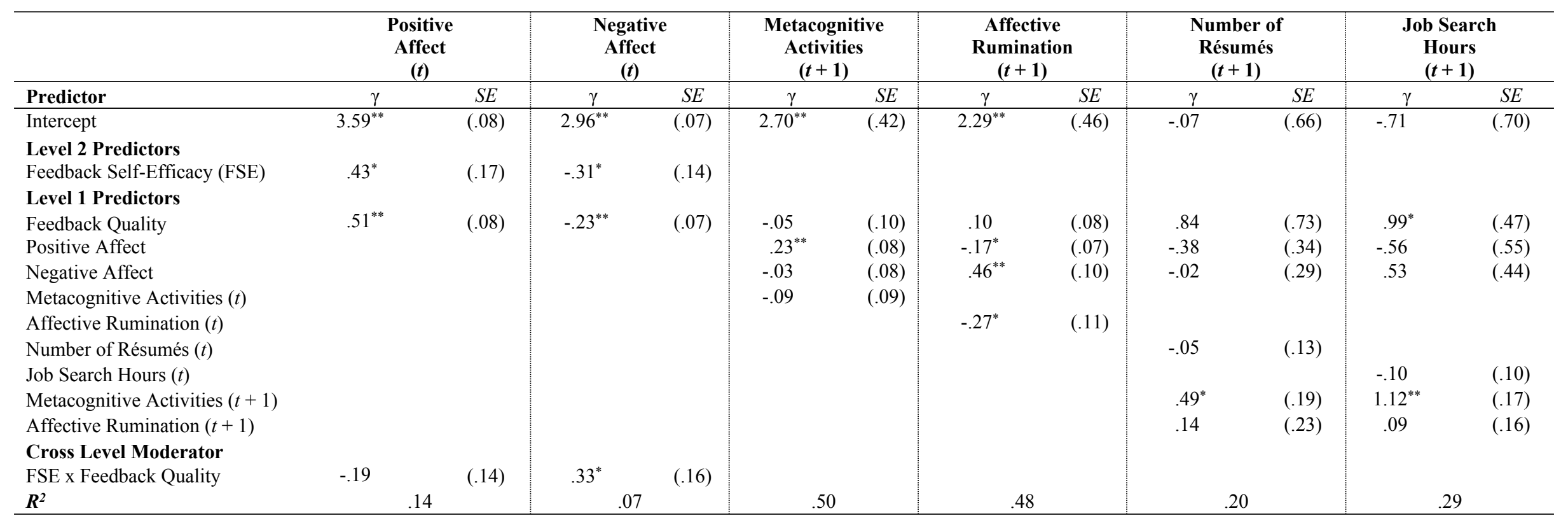

Note. Level $1 n=306$ (after accounting for lagged data). Level $2 n=93$. Level 1 exogenous variables were group-mean centered; feedback self-efficacy was grand-mean centered. $S E=$ standard error. Cognitive and behavioral processes at $t$ and direct effects were modeled as fixed effects (Lanaj et al., 2016; Wang et al., 2013). The $R^{2}$ captures the percentage of within-person variance explained in each outcome of interest and was calculated using the Snijders and Bosker (1999) formula. We also tested a model that controlled for gender and GPA (at Level 2) as well as week of the study and the number of organizations participants received feedback from (at Level 1); results of this model did not affect any conclusions drawn. Thus, we omitted these variables from our multilevel path analysis. These results are available from the authors upon request.

${ }^{*} p<.05,{ }^{* *} p<.01$. 


\section{Table 3}

Results of Bias-Corrected Indirect and Conditional Indirect Effects from Multilevel Path Analysis

\begin{tabular}{|c|c|c|c|}
\hline Indirect Effect & Feedback Self-Efficacy & Estimate & $95 \% C I$ \\
\hline Feedback quality $\rightarrow$ Metacognitive strategies (via PA) & -- & $.11^{*}$ & {$[.039, .213]$} \\
\hline \multirow[t]{3}{*}{ Feedback quality $\rightarrow$ Metacognitive strategies (via NA) } & -- & .01 & {$[-.025, .051]$} \\
\hline & Low & .01 & {$[-.042, .091]$} \\
\hline & High & .00 & {$[-.008, .038]$} \\
\hline Feedback quality $\rightarrow$ Affective rumination (via PA) & -- & $-.09^{*}$ & {$[-.175,-.019]$} \\
\hline \multirow[t]{3}{*}{ Feedback quality $\rightarrow$ Affective rumination (via NA) } & -- & $-.11^{*}$ & {$[-.201,-.039]$} \\
\hline & Low & $-.18^{*}$ & {$[-.337,-.077]$} \\
\hline & High & -.04 & {$[-.138, .047]$} \\
\hline Feedback quality $\rightarrow$ Résumés (via PA and Metacognitive strategies) & -- & $.06^{*}$ & {$[.015, .132]$} \\
\hline \multirow[t]{3}{*}{ Feedback quality $\rightarrow$ Résumés (via NA and Metacognitive strategies) } & -- & .00 & {$[-.011, .032]$} \\
\hline & Low & .01 & {$[-.015, .104]$} \\
\hline & High & .00 & {$[-.003, .022]$} \\
\hline Feedback quality $\rightarrow$ Hours (via PA and Metacognitive strategies) & -- & $.13^{*}$ & {$[.045, .253]$} \\
\hline \multirow[t]{3}{*}{ Feedback quality $\rightarrow$ Hours (via NA and Metacognitive strategies) } & -- & .01 & {$[-.029, .058]$} \\
\hline & Low & .02 & {$[-.049, .101]$} \\
\hline & High & .00 & {$[-.009, .045]$} \\
\hline Feedback quality $\rightarrow$ Résumés (via PA and Affective rumination) & -- & -.01 & {$[-.075, .023]$} \\
\hline \multirow[t]{3}{*}{ Feedback quality $\rightarrow$ Résumés (via NA and Affective rumination) } & -- & -.02 & {$[-.085, .027]$} \\
\hline & Low & -.03 & {$[-.141, .050]$} \\
\hline & High & -.01 & {$[-.069, .010]$} \\
\hline Feedback quality $\rightarrow$ Hours (via PA and Affective rumination) & -- & -.01 & {$[-.052, .017]$} \\
\hline \multirow[t]{3}{*}{ Feedback quality $\rightarrow$ Hours (via NA and Affective rumination) } & -- & -.01 & {$[-.062, .020]$} \\
\hline & Low & -.02 & {$[-.095, .038]$} \\
\hline & High & .00 & {$[-.046, .006]$} \\
\hline
\end{tabular}

Note. Bias-corrected indirect effects and conditional indirect effects. Confidence intervals are based on 20,000 Monte Carlo bootstrap samples. PA = Positive affect, $\mathrm{NA}=$ Negative affect, $\mathrm{CI}=$ Confidence interval. All indirect effects were calculated accounting for direct effects. Because the interaction of feedback quality and feedback self-efficacy on positive affect was not significant, we did not calculate conditional indirect effects for this specific path.

${ }^{*} p<.05$. 


\section{Figure 1}

Conceptual Model and Multilevel Path Analysis Results

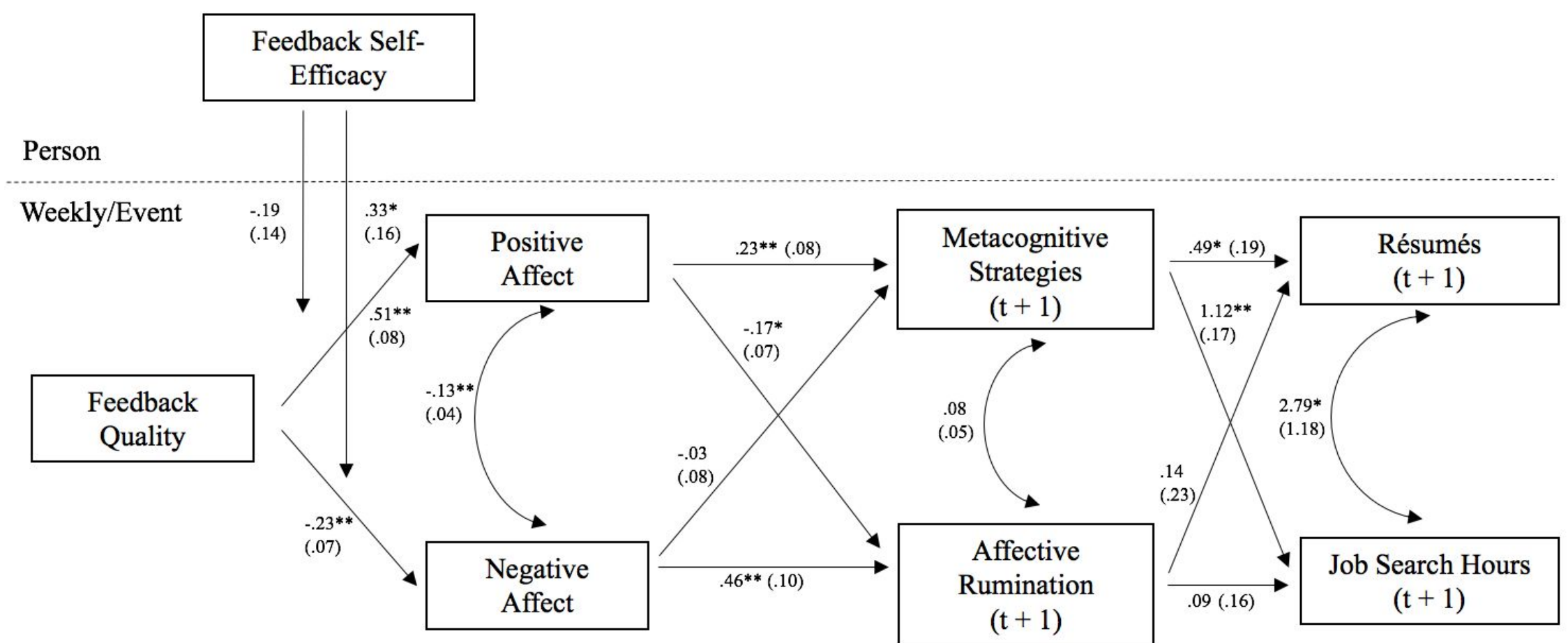

Note. Values in parentheses are standard errors. The model reflects analyses that includes all possible direct effects from predictor to outcome variables. Additionally, this model includes lagged (i.e., the previous week's) metacognitive strategies, affective rumination, résumés, and job search hours as predictors of this week's cognitive strategies and job search behaviors $(t \rightarrow t+1)$. We also tested a model that controlled for gender and GPA (at Level 2) and week of the study and the number of organizations participants received feedback from (at Level 1); results of this model did not affect any conclusions drawn. These results are available from the authors upon request.

${ }^{*} p<.05,{ }^{* *} p<.01$. 
Feedback and Job Search Processes 61

\section{Figure 2}

Cross-Level Moderating Effect of Feedback Self-Efficacy and Feedback Quality on Negative Affect

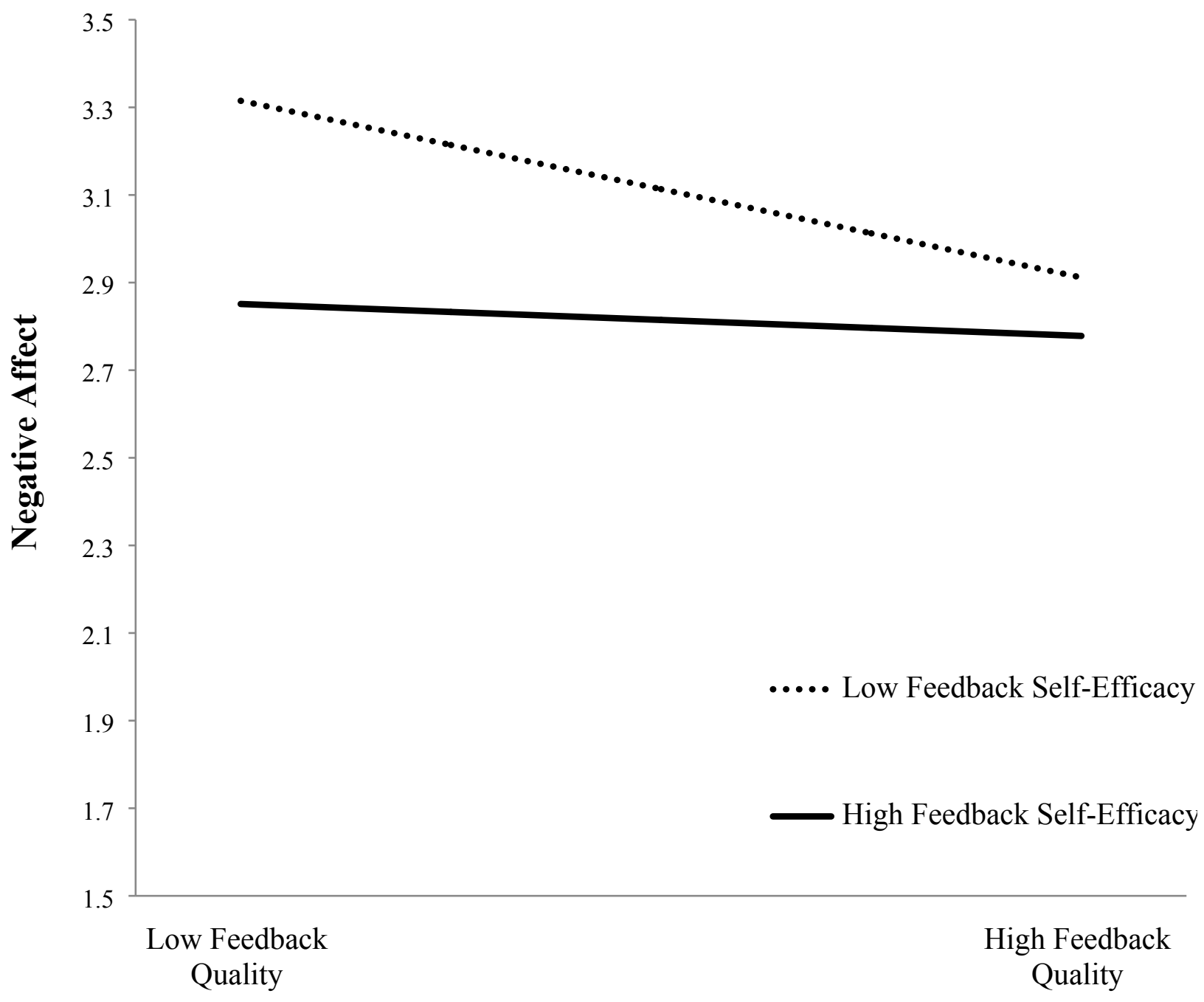

